Atmos. Chem. Phys., 17, 13967-13982, 2017

https://doi.org/10.5194/acp-17-13967-2017

(c) Author(s) 2017. This work is distributed under

the Creative Commons Attribution 3.0 License.

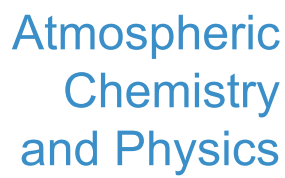

(c) (P)

\title{
Potential influences of neglecting aerosol effects on the NCEP GFS precipitation forecast
}

\author{
Mengjiao Jiang ${ }^{1,2}$, Jinqin Feng ${ }^{3}$, Zhanqing $\mathrm{Li}^{1,2}$, Ruiyu $\mathrm{Sun}^{4}$, Yu-Tai Hou ${ }^{4}$, Yuejian $\mathrm{Zhu}^{4}$, Bingcheng Wan ${ }^{5}$, \\ Jianping Guo ${ }^{6}$, and Maureen Cribb ${ }^{2}$ \\ ${ }^{1}$ State Key Laboratory of Earth Surface Processes and Resource Ecology, College of Global Change and Earth System \\ Science, Beijing Normal University, Beijing, China \\ ${ }^{2}$ Department of Atmospheric and Oceanic Science and ESSIC, University of Maryland, College Park, Maryland, USA \\ ${ }^{3}$ Longyan Meteorological Office of Fujian Province, Longyan, Fujian, China \\ ${ }^{4}$ Environmental Modeling Center, National Centers for Environmental Prediction, National Oceanic and Atmospheric \\ Administration, College Park, Maryland, USA \\ ${ }^{5}$ State Key Laboratory of Atmospheric Boundary Layer Physics and Atmospheric Chemistry, Institute of Atmospheric \\ Physics, Chinese Academy of Sciences, Beijing, China \\ ${ }^{6}$ State Key Laboratory of Severe Weather, Chinese Academy of Meteorological Sciences, Beijing, China
}

Correspondence to: Zhanqing Li (zhanqing@umd.edu)

Received: 22 March 2017 - Discussion started: 2 May 2017

Revised: 29 August 2017 - Accepted: 3 October 2017 - Published: 23 November 2017

\begin{abstract}
Aerosol-cloud interactions (ACIs) have been widely recognized as a factor affecting precipitation. However, they have not been considered in the operational $\mathrm{Na}$ tional Centers for Environmental Predictions Global Forecast System model. We evaluated the potential impact of neglecting ACI on the operational rainfall forecast using groundbased and satellite observations and model reanalysis. The Climate Prediction Center unified gauge-based precipitation analysis and the Modern-Era Retrospective analysis for Research and Applications Version 2 aerosol reanalysis were used to evaluate the forecast in three countries for the year 2015. The overestimation of light rain $(47.84 \%)$ and underestimation of heavier rain $(31.83,52.94$, and $65.74 \%$ for moderate rain, heavy rain, and very heavy rain, respectively) from the model are qualitatively consistent with the potential errors arising from not accounting for ACI, although other factors cannot be totally ruled out. The standard deviation of the forecast bias was significantly correlated with aerosol optical depth in Australia, the US, and China. To gain further insight, we chose the province of Fujian in China to pursue a more insightful investigation using a suite of variables from gauge-based observations of precipitation, visibility, water vapor, convective available potential energy (CAPE), and satellite datasets. Similar forecast biases were found:
\end{abstract}

over-forecasted light rain and under-forecasted heavy rain. Long-term analyses revealed an increasing trend in heavy rain in summer and a decreasing trend in light rain in other seasons, accompanied by a decreasing trend in visibility, no trend in water vapor, and a slight increasing trend in summertime CAPE. More aerosols decreased cloud effective radii for cases where the liquid water path was greater than $100 \mathrm{~g} \mathrm{~m}^{-2}$. All findings are consistent with the effects of ACI, i.e., where aerosols inhibit the development of shallow liquid clouds and invigorate warm-base mixed-phase clouds (especially in summertime), which in turn affects precipitation. While we cannot establish rigorous causal relations based on the analyses presented in this study, the significant rainfall forecast bias seen in operational weather forecast model simulations warrants consideration in future model improvements.

\section{Introduction}

Aerosols affect precipitation by acting as cloud condensation nuclei (CCN) and ice nuclei (IN), which can influence cloud microphysics (Twomey et al., 1984) and cloud lifetime (Albrecht, 1989). By absorbing and scattering radiation in the atmosphere, aerosols can alter the thermal and dy- 
namic conditions of the atmosphere. The two types of effects are broadly referred to as aerosol-cloud interactions (ACIs) and aerosol-radiation interactions (ARIs) (Intergovernmental Panel on Climate Change, 2013). Both can influence precipitation (Rosenfeld et al., 2008) and many other meteorological variables to the extent that they may account for the considerable changes in climate experienced in Asia over the past half century (Li et al., 2016).

The impact of aerosols on precipitation via cloud microphysics occurs through warm-rain and cold-rain processes, as reviewed by Tao et al. (2012). In the warm-rain process, the competition for water vapor leads to a greater number of cloud drops with smaller sizes as the aerosol loading increases. This decreases the collision efficiency because of the low fall speed and low droplet-collecting efficiency. Rain formation is thus slowed down. Also, a heavier aerosol loading narrows the cloud drop-size spectrum, lowering the coalescence and collision efficiencies. The delay in precipitation formation from the warm-rain process enhances condensation and freezing and, ultimately, leads to the release of extra latent heat above the $0^{\circ} \mathrm{C}$ isotherm (Andreae et al., 2004; Rosenfeld et al., 2008), favoring mixed-phase and cold rainfall processes. ARIs also affect precipitation. First, solar radiation absorbed by aerosols may warm up a cloud droplet enough to evaporate it (Ackerman et al., 2000). Second, the heating of an aerosol layer due to absorption and cooling of the surface because of the reduction in radiation reaching the ground stabilizes the lower boundary-layer atmosphere and suppresses the formation and development of low clouds whose occurrence decreases with increasing aerosol loading (Li et al., 2011). The suppressed convection by ARI may also lead to rainfall enhancement downwind of polluted places (Carrió et al., 2010; Fan et al., 2015). The combination of ARI and ACI leads to a non-monotonic response of rainfall to aerosols: increasing first and then decreasing (Jiang et al., 2016) because the ACI and ARI are most significant for low and high aerosol loadings, respectively (Rosenfeld et al., 2008; Koren et al., 2008; Fan et al., 2016).

Most findings concerning the aerosol suppression of clouds and precipitation are associated with stratocumulus clouds, cumulus clouds, and shallow convection (Albrecht, 1989; Rosenfeld, 2000; Jiang et al., 2006; Xue and Feingold, 2006; Khain et al., 2008), whereas those of enhanced rainfall are associated with deep convective clouds (Koren et al., 2005; Lin et al., 2006; Bell et al., 2008; Rosenfeld et al., 2008). Li et al. (2011) used 10 years of ground-based observations to examine the long-term impact of aerosols on precipitation and found rainfall enhancement in mixed-phase warm-base clouds and suppression in liquid clouds. Van den Heever et al. (2011) underlined the importance of cloud type in dealing with the impact of aerosols on precipitation.

Forecasting rainfall is most challenging and important in numerical weather prediction (NWP). In the current Global Forecast System (GFS) model, aerosols are only considered in the radiation scheme on a climatological scale. ARIs are only considered off-line and are not coupled with the dynamic system. ACIs have not yet been accounted for. To improve the forecast accuracy, a suite of new physical schemes are being implemented in the National Centers for Environmental Prediction (NCEP)'s Next Generation Global Prediction System. The goal of modifying the current forecast model is to improve physical parameterizations in a way that allows for efficient, accurate, and more complete representations of physical processes and their interactions including at least some of the aforementioned aerosol mechanisms.

As a first step, the goal of the present study is to evaluate current operational GFS forecast results (before any ACIs are introduced) to see if any systematic precipitation biases bear resemblance to aerosol perturbations. A gross evaluation of the GFS model forecast results in three countries (China, the US, and Australia) being chosen because they cover all hemispheres and represent different atmospheric and environmental conditions. Moreover, there are the US Department of Energy's Atmospheric Radiation Measurement (ARM) observations in all three countries that will be used in follow-on studies to gain a deeper insight into causal relationships and the impact of different parameterization schemes. Descriptions of the operational GFS model, datasets, and the evaluation strategy and statistical method used are presented in Sect. 2. Results of the evaluation and possible explanations are given in Sect. 3. A summary of the research and discussion are given in Sect. 4.

\section{Model, datasets, and methodology}

\subsection{Description of the NCEP GFS model}

The NCEP GFS model is a global spectral forecast model (spherical harmonic basis functions) that has been described and evaluated over the years (e.g., Kanamitsu, 1989; Yang et al., 2006; Sela, 2009; Yoo et al., 2012, 2013). Shortwave and longwave radiation are parameterized using the Rapid Radiative Transfer Models (RRTMG) RRTMG_SW (v3.8) and RRTMG_LW (updated based on AER's version 4.8), respectively, developed at AER Inc. (http://www.emc.ncep. noaa.gov/GFS/doc.php). A monthly climatology of aerosols composed of five primary species similar to those in the Goddard Chemistry Aerosol Radiation and Transport model (GOCART; Chin et al., 2002) was used. One or two major components in each grid (based on climatology) were chosen for both longwave and shortwave radiative transfer calculations. In the planetary boundary layer (PBL), a hybrid eddydiffusivity mass flux PBL parameterization (Han et al., 2016) was incorporated to replace the previous PBL scheme (Troen and Mahrt, 1986; Hong and Pan, 1996). A modified version (Han and Pan, 2011) of the simplified Arakawa-Schubert scheme (Arakawa and Schubert, 1974; Grell, 1993; Pan and $\mathrm{Wu}, 1995)$ is used for deep convection in the GFS model. The new shallow convection scheme (Han and Pan, 2011) 
uses a bulk mass-flux parameterization, which is similar to the deep convection scheme, but with a cloud-top limit of $700 \mathrm{hPa}$ and different specifications on entrainment, detrainment, and mass flux at the cloud base. A prognostic cloud water scheme (Sundqvist et al., 1989; Zhao and Carr, 1997; Moorthi et al., 2001) was added in May 2001. Grid-scale precipitation is the sink of cloud condensate and is diagnostically calculated from cloud condensate. It is parameterized following Zhao and Carr (1997) for ice (snow), evaporation of rain and snow, and the melting of snow and following Sundqvist et al. (1989) for liquid water (rain) (GCWM Branch, EMC, 2003).

\subsection{Descriptions of datasets used}

The datasets used include Modern-Era Retrospective analysis for Research and Applications Version 2 (MERRA-2) aerosol optical depth (AOD) data, Climate Prediction Center (CPC) unified gauge-based precipitation data, and the NCEP GFS precipitation forecast data for the year 2015 in three countries: China, the US, and Australia. Other datasets used include long-term NCEP Global Ensemble Forecast System (GEFS) precipitation forecast data, ground-based observations of precipitation and visibility, water vapor and convective available potential energy (CAPE) sounding datasets, and satellite-retrieved aerosol and cloud properties for a small region of Fujian Province in China chosen for more detailed study.

\subsubsection{NASA MERRA-2 aerosol reanalysis}

The MERRA-2 aerosol reanalysis (Randles et al., 2016) is an upgrade of the off-line aerosol reanalysis called MERRAero (da Silva et al., 2011; Rienecker et al., 2011; Jiang et al., 2016). The aerosol module in MERRAero is based on the GOCART model (Chin et al., 2002). The AOD observing system sensors extend from the Moderate Resolution Imaging Spectroradiometer (MODIS) Neural Net Retrieval (NNR) in MERRAero to a combination of the Advanced Very High Resolution Radiometer (AVHRR) NNR, the Aerosol Robotic Network (AERONET), the Multi-angle Imaging SpectroRadiometer (MISR), the MODIS Terra NNR, and the MODIS Aqua NNR in the MERRA-2 aerosol reanalysis. More details about the MERRA-2 aerosol reanalysis can be found in Randles et al. (2016). Three-hourly total aerosol extinction AOD data at $550 \mathrm{~nm}$ at a resolution of $0.625^{\circ} \times 0.5^{\circ}$ for the year 2015 are used in this study.

\subsubsection{CPC unified gauge-based analysis of global daily precipitation}

A unified suite of precipitation analysis products that include a gauge-based analysis of global daily precipitation over land was assembled at NOAA's CPC (https://climatedataguide.ucar.edu/climate-data/ cpc-unified-gauge-based-analysis-global-daily-precipitation).
Over 17000 station reports were first collected from multiple sources. Quality control was performed through comparisons with other sources of data, e.g., radar, satellite, numerical models, independent nearby stations, and historical precipitation records. Post quality-control corrected reports are interpolated to create the analyzed fields. Orographic effects are considered in this step (Xie et al., 2007). Finally, the daily analysis is constructed and released at a $0.5^{\circ} \times 0.5^{\circ}$ resolution (https://climatedataguide.ucar.edu/climate-data/ cpc-unified-gauge-based-analysis-global-daily-precipitation). Daily precipitation data for the year 2015 are used in this study.

\subsubsection{NCEP GFS/GEFS forecast datasets}

The NWP model forecast data used are 3-hourly rainfall forecasts from the NOAA NCEP GFS model initialized at 00:00 coordinated universal time (UTC) and accumulated for $24 \mathrm{~h}$ in the three countries chosen for study. The relative humidity (RH) at $850 \mathrm{hPa}$ and the liquid water path (LWP) calculated following Yoo et al. (2012) are used, corresponding to the precipitation record in the three countries at a $0.5^{\circ} \times 0.5^{\circ}$ latitude-longitude resolution. For the part of the study focused on Fujian Province, China, the long-term NWP model reforecast precipitation amount accumulated over the period of 12 to $36 \mathrm{~h}$ from 00:00 UTC at a $1^{\circ} \times 1^{\circ}$ latitude-longitude resolution for the years 1985 to 2010 is used.

\subsubsection{Long-term ground-based observations in Fujian Province, China}

Ground meteorological data acquired in Fujian Province from 1980 to 2009 are used in this study. Figure 1 shows the locations of the 67 meteorological stations measuring precipitation. Sixteen of these stations also collect visibility data four times a day. Daily mean data are used here. Visibility has been used as proxy for aerosol loading in China in several studies (Rosenfeld et al., 2007; Yang et al., 2013; Yang and $\mathrm{Li}, 2014)$. The main advantage is the long measurement record under all sky conditions. However, there are some limitations, e.g., the uncertainty due to humans making the observations and the influence of aerosol hygroscopic growth. To remove the humidity influence on visibility, visibility was corrected for RH (Charlson, 1969; Appel et al., 1985) using the formula adopted by Rosenfeld et al. (2007) when RH falls between 40 and $99 \%$ :

$\frac{V_{\text {ori }}}{V_{\text {cor }}}=0.26+0.4285 \lg (100-\mathrm{RH})$,

where $\mathrm{RH}$ is in percent and $V_{\text {ori }}$ and $V_{\text {cor }}$ are the originally uncorrected and corrected visibilities, respectively. Only non-rainy data were used.

To analyze water vapor and atmospheric stability effects on precipitation, data collected twice a day (at 00:00 and 12:00 UTC) from three atmospheric sounding stations (Xiamen, $24.48^{\circ} \mathrm{N}, 118.08^{\circ} \mathrm{E}$; Shaowu, $27.33^{\circ} \mathrm{N}, 117.46^{\circ} \mathrm{E}$; 


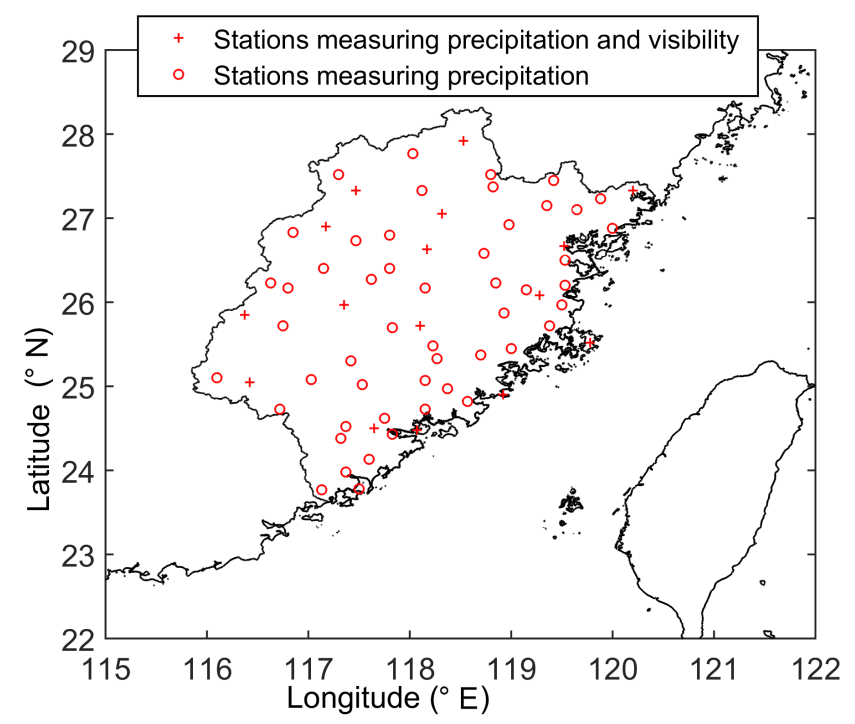

Figure 1. Locations of 67 stations measuring precipitation in Fujian Province. Plus symbols show the locations of the 16 stations where visibility measurements are also made. This figure was plotted using the equidistant cylindrical projection.

Fuzhou, $26.08^{\circ} \mathrm{N}, 119.28^{\circ} \mathrm{E}$ ) are used to calculate trends in precipitable water vapor and CAPE. Daily precipitable water and CAPE values are the mean of the two measurements made per day.

\subsubsection{Satellite datasets of aerosol and cloud properties in Fujian Province, China}

CloudSat and Cloud Aerosol Lidar and Infrared Pathfinder Satellite Observation (CALIPSO) data from 2006 to 2010 amassed over Fujian Province (22.5-28.5 N, 114.5$120.5^{\circ} \mathrm{E}$ ) are used to extract cloud-top and cloud-base height information. CloudSat-CALIPSO retrievals of cloud-top and base heights are converted to temperatures using temperature profiles from the European Center for Medium-range Weather Forecasting Auxiliary product (ECMWF-AUX). The converted cloud-top and cloud-base temperatures are used for cloud type classification. The classification of different cloud types is summarized in Table 1 and introduced in Sect. 2.3.2. Only single-layer clouds detected by the CloudSat are chosen here.

Aqua MODIS retrievals of cloud droplet size and LWP for liquid clouds (clouds with cloud-top temperatures (CTTs) greater than 273 K) collected over Fujian Province from 2003 to 2012 are used. Errors in satellite retrievals of AOD such as cloud contamination (Kaufman et al., 2005; Zhang et al., 2005) introduce uncertainties in the aerosol-cloud relationship (Gryspeerdt et al., 2014a, b). We use MODIS Level 3 AOD with AOD > 0.6 excluded and not the higher-resolution Level 2 product to reduce the possibility of cloud contamination (Niu and Li, 2012) in AOD retrievals.
Table 1. Definitions of warm- and cold-base mixed-phase clouds and liquid clouds.

\begin{tabular}{lrr}
\hline & $\begin{array}{r}\text { Cloud-base } \\
\text { temperature } \\
\left({ }^{\circ} \mathrm{C}\right)\end{array}$ & $\begin{array}{r}\text { Cloud-top } \\
\text { temperature } \\
\left({ }^{\circ} \mathrm{C}\right)\end{array}$ \\
\hline $\begin{array}{l}\text { Deep mixed-phase clouds } \\
\text { with warm bases }\end{array}$ & $>15$ & $<-4$ \\
$\begin{array}{l}\text { Shallow mixed-phase } \\
\text { clouds with cold bases }\end{array}$ & $0-15$ & $<-4$ \\
Liquid clouds & $>0$ & $>0$ \\
\hline
\end{tabular}

\subsection{Methodology}

\subsubsection{Spatial and temporal matching of model and observation data}

CPC unified gauge-based daily precipitation data at a $0.5^{\circ} \times 0.5^{\circ}$ latitude-longitude resolution in the three countries for the year 2015 are used. GFS model grid 004 data at the same latitude-longitude resolution $\left(0.5^{\circ} \times 0.5^{\circ}\right)$ are also used. Forecast precipitation for a 1-day accumulation generated at 3-hourly intervals (e.g., at 03:00, 06:00, 09:00, $12: 00,15: 00,18: 00,21: 00,24: 00$ UTC), starting from the control time of 00:00 UTC, is used to match the corresponding gauge-based observations. The MERRA-2 aerosol analysis is not coupled with GFS simulations. Daily MERRA-2 $\mathrm{AOD}$ is at a resolution of $0.625^{\circ} \times 0.5^{\circ}$ and is interpolated to the CPC and GFS precipitation resolution using a linear interpolation method. The spatial and temporal resolutions of the matched datasets are $0.5^{\circ} \times 0.5^{\circ}$ and are generated for each day. There are $\sim 3686000$ grid points in total.

For the long-term analysis focused on Fujian, China, the NWP model reforecast precipitation amount accumulated over the period of 12 to $36 \mathrm{~h}$ from the 00:00 UTC run at 6hourly intervals and at a $1^{\circ} \times 1^{\circ}$ latitude-longitude resolution for the years 1985 to 2010 is used to calculate the modeled daily precipitation amount in each grid box. The calculated daily precipitation amounts from the model forecast are interpolated to match the long-term ground-based precipitation observations recorded at each of the 67 stations in the study region of Fujian, China (Fig. 1). There are 9495 days in total with matched data.

\subsubsection{Rainfall level classification and cloud type classification}

Based on the definitions of the China Meteorological Administration, precipitation data are classified into four groups according to the daily rain amount: light rain $(0.1-$ $\left.9.9 \mathrm{~mm} \mathrm{~d}^{-1}\right)$, moderate rain $\left(10-24.9 \mathrm{~mm} \mathrm{~d}^{-1}\right)$, heavy rain $\left(25-49.9 \mathrm{~mm} \mathrm{~d}^{-1}\right)$, and very heavy rain $\left(\geq 50 \mathrm{~mm} \mathrm{~d}^{-1}\right)$. Rain gauge data are usually used as reference data in weather forecast and model evaluations because they come from direct 
Table 2. Contingency table.

\begin{tabular}{|c|c|c|c|}
\hline & \multicolumn{2}{|c|}{ Observed } \\
\hline & & Observed yes & Observed no \\
\hline 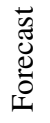 & $\begin{array}{l}\text { Forecast yes } \\
\text { Forecast no }\end{array}$ & $\begin{array}{l}\text { Hits } \\
\text { Misses }\end{array}$ & $\begin{array}{l}\text { False alarms } \\
\text { Correct negatives }\end{array}$ \\
\hline
\end{tabular}

physical records (Tapiador et al., 2012). The most commonly used rain detector is the tipping bucket. Once the bucket is filled $(0.1 \mathrm{~mm})$, the bucket is emptied and produces a signal. This process repeats until precipitation stops. Light rain less than $0.1 \mathrm{~mm}$ cannot be measured. Therefore, the definition of light rain is $0.1-9.9 \mathrm{~mm} \mathrm{~d}^{-1}$.

Table 1 summarizes the cloud types considered in the $\mathrm{Fu}-$ jian Province analysis. Deep mixed-phase clouds are defined as clouds with cloud-base temperatures (CBTs) $>15^{\circ} \mathrm{C}$ and CTTs $<-4{ }^{\circ} \mathrm{C}$; shallow mixed-phase clouds are defined as clouds with CBTs ranging from 0 to $15^{\circ} \mathrm{C}$ and CTTs $<$ $-4{ }^{\circ} \mathrm{C}$; and pure liquid clouds are defined as clouds with CBTs $>0{ }^{\circ} \mathrm{C}$ and CTTs $>0{ }^{\circ} \mathrm{C}$ (Li et al., 2011; Niu and $\mathrm{Li}$, 2012).

\subsubsection{Evaluation methods}

Quantitative precipitation forecast scores developed by NCEP are used in the evaluation. Table 2 is a contingency table based on documents from the World Climate Research Programme (http://www.cawcr.gov.au/projects/verification/ \#Methods_for_dichotomous_forecasts). The most commonly used statistical scores are the equitable threat score (ETS), which is also called the Gilbert skill score, and the bias score (BIAS). The ETS is given by

$\mathrm{ETS}=\frac{H-H_{\text {random }}}{H+m+f-H_{\text {random }}}$,

where $H$ represents hits, $f$ represents false alarms, and $m$ represents misses. $H_{\text {random }}$ is given by

$H_{\text {random }}=\frac{(H+m) \times(H+f)}{\text { TOTAL }}$.

Its values range from $-1 / 3$ to 1 and a perfect score is 1 . The BIAS is expressed as

BIAS $=\frac{H+f}{H+m}$.

Its values range from 0 to infinity. A perfect score is 1 . A BIAS $<1$ indicates under-forecasting and a BIAS $>1$ indicates over-forecasting.

Under limited ranges of LWP or RH, the top and bottom one-third of AOD values denote polluted and clean subsets of data. To obtain the forecast skill under a particular pollution condition, the ETS and the BIAS for clean and polluted conditions are calculated as

$$
\begin{aligned}
& <\mathrm{ETS}>_{i, j, m}=(\mathrm{ETS})_{i, j, m}, \\
& <\mathrm{BIAS}>_{i, j, m}=(\mathrm{BIAS})_{i, j, m},
\end{aligned}
$$

for the index of precipitation threshold $(i)$, RH or LWP $(j)$, and clean or polluted scenario $(m)$.

\subsubsection{Statistical method}

The standard deviation of the precipitation bias between the GFS model and CPC gauge data is calculated as

$S=\sqrt{\frac{\sum(x-r)^{2}}{n-1}}$,

where $x$ is the forecast bias on a single day, $n$ is equal to 364 days, and $r$ is the mean forecast bias. Pearson's method is used to calculate the linear correlation coefficient of the relationship between the standard deviation of the forecast difference and AOD. A $t$ test is applied with the $p$ value set to 0.05 .

The relative difference between the forecast precipitation and observations is calculated as

$\Delta P=\frac{P_{\mathrm{GFS} / \mathrm{GEFS}}-P_{\mathrm{OBV}}}{P_{\mathrm{OBV}}} \times 100 \%$,

where $P_{\mathrm{GFS} / \mathrm{GEFS}}$ refers to the forecast precipitation and $P_{\mathrm{OBV}}$ refers to the precipitation from gauge-based observations.

For the long-term analysis, trends in a particular parameter are defined as the relative change in the parameter (in \%) over each successive decade (Lin and Zhao, 2009). The MannKendall method is used to test the significance of the trend.

\section{Results}

\subsection{Evaluation of GFS precipitation using the CPC gauge-based analysis}

\subsubsection{Annual mean patterns}

The CPC gauge-based precipitation analysis from 2015 is used to evaluate the GFS precipitation forecast. Figure 2 shows the annual mean precipitation difference between the GFS model and the CPC analysis for three countries, i.e., China, the US, and Australia, for the year 2015. Values above (below) 0 represent the overestimation (underestimation) of precipitation. In China (Fig. 2a), the GFS model overestimates the mean daily rainfall mostly in southwest China, especially in Sichuan, Yunnan, and Guizhou provinces (by $\sim 3 \mathrm{~mm} \mathrm{~d}^{-1}$ ), and in northwest China, where rain events are scarcer. Rainfall is underestimated over the 

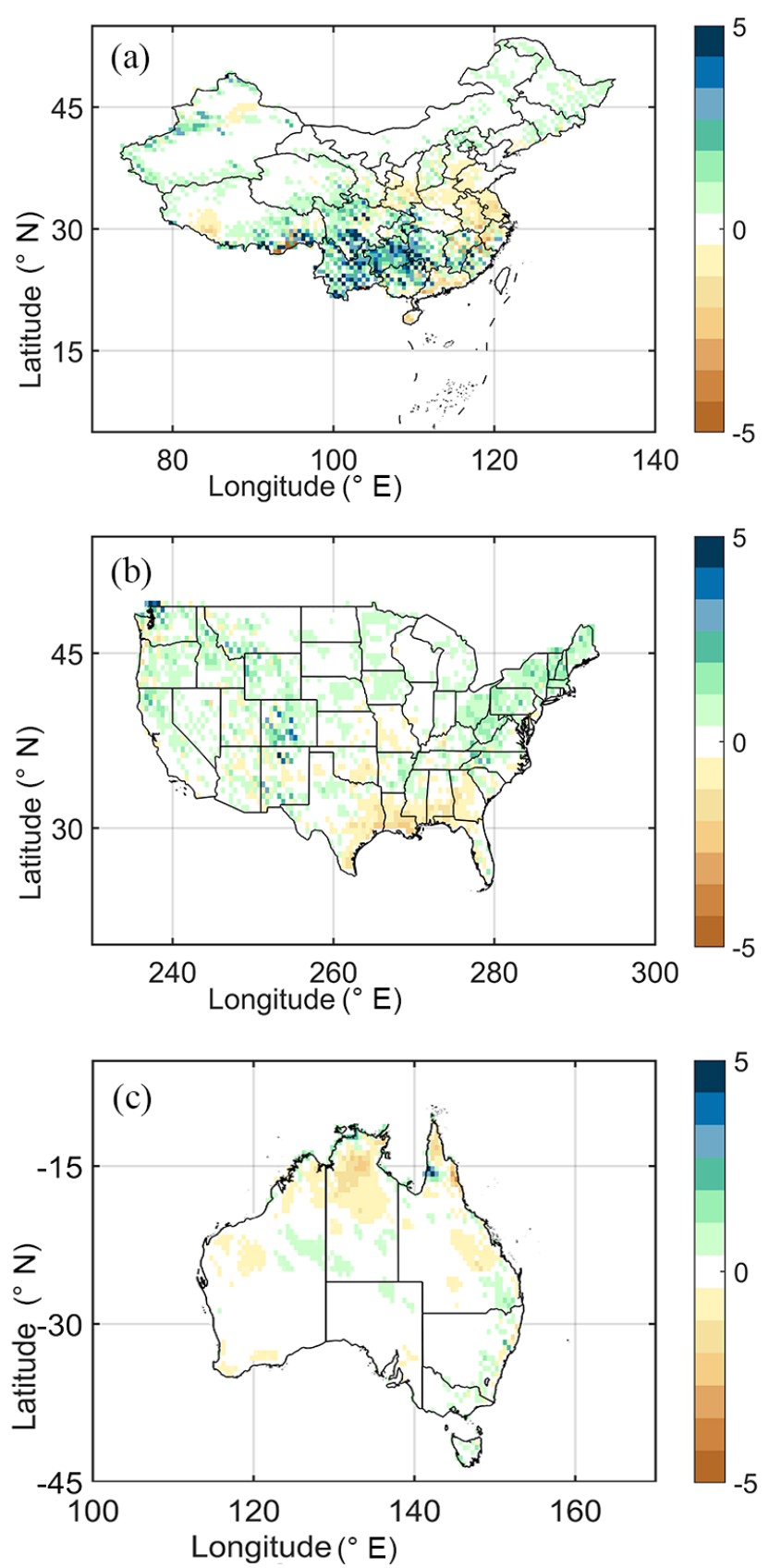

Figure 2. Annual mean precipitation differences (in $\mathrm{mm} \mathrm{d}^{-1}$ ) between the GFS model forecast and the CPC analysis in three countries: (a) China, (b) the contiguous US, and (c) Australia. Data are from the year 2015. This figure was plotted using the equidistant cylindrical projection.

Yangtze River Delta region and the eastern coast of China. In the US (Fig. 2b), the GFS model overestimates precipitation by about $1-2 \mathrm{~mm} \mathrm{~d}^{-1}$ in most regions and underestimates precipitation along the coastline of the Gulf of Mexico (by $\sim 1 \mathrm{~mm} \mathrm{~d}^{-1}$ ). In Australia (Fig. 2c), the forecast performance is good. In northern Australia, the underestimation of precipitation is around $2 \mathrm{~mm} \mathrm{~d}^{-1} . Z$ scores were calculated
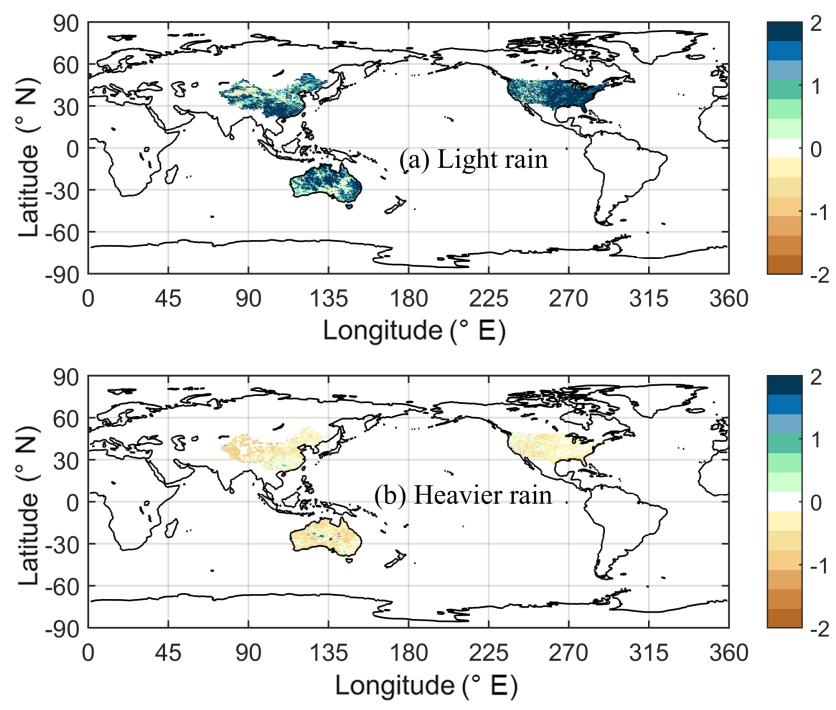

Figure 3. Annual mean relative difference (in $\mathrm{mm} \mathrm{d}^{-1}$ ) between forecast and observed precipitation for (a) light rain $\left(<10 \mathrm{~mm} \mathrm{~d}^{-1}\right)$ and (b) heavier rain $\left(>10 \mathrm{~mm} \mathrm{~d}^{-1}\right)$. Data are from the year 2015 . This figure was plotted using the equidistant cylindrical projection.

to test the significance of the annual mean difference in the daily rainfall amount between the GFS model forecast and the CPC analysis. $Z$ values range from -0.4803 to 0.8534 over the grids in the three countries. Because the $Z$-score values are less than 2 , this indicates that the mean difference is not significant at the $2 \sigma$ level. Therefore, the forecast performance of the GFS model with regard to the annual mean daily rainfall in the three countries is sound with reference to the gauge-based CPC rainfall analysis.

\subsubsection{Different rainfall intensities}

Figure 3 shows the annual mean relative difference between forecast precipitation and observations for light rain $\left(0.1-10 \mathrm{~mm} \mathrm{~d}^{-1}\right)$ and heavier rain $\left(>10 \mathrm{~mm} \mathrm{~d}^{-1}\right)$. The GFS model overestimates light rain in most places (Fig. 3a) and underestimates heavier rain (Fig. 3b). This suggests that both the overestimation of light rain and underestimation of moderate rain, heavy rain, and very heavy rain contribute to the forecast bias. Figure 4 shows the mean relative difference between forecast and observed daily precipitation amounts for different rain intensities in the three countries for the whole year (Fig. 4a) and for summer only (Fig. 4b). GFS forecasts overestimate light rain by $47.84 \%$ and underestimate moderate rain, heavy rain, and very heavy rain by $31.83,52.94$, and $65.74 \%$, respectively (Fig. 4a). The underestimation of precipitation in summer is larger for moderate rain $(32.93 \%)$, heavy rain (55.19\%), and very heavy rain (66.93\%; Fig. 4b). These model biases are caused by many factors that are beyond the scope of this paper to examine. Our focus is on any potential contribution of neglecting aerosol effects to the bi- 

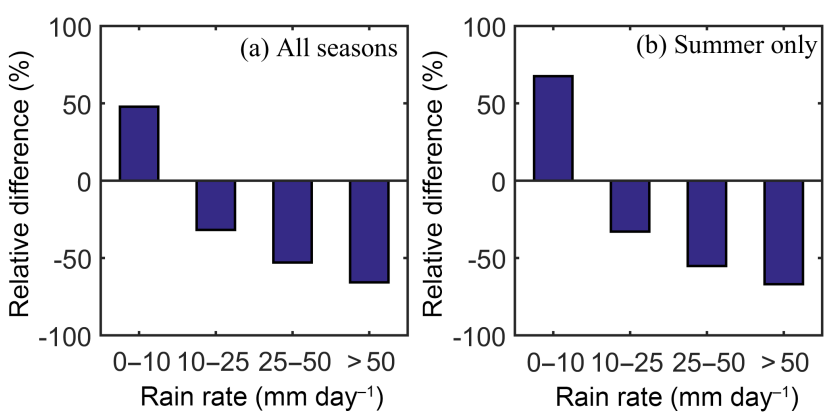

Figure 4. Mean relative difference in precipitation between forecast and observed daily light $\left(<10 \mathrm{~mm} \mathrm{~d}^{-1}\right)$, moderate $\left(10-25 \mathrm{~mm} \mathrm{~d}^{-1}\right)$, heavy $\left(25-50 \mathrm{~mm} \mathrm{~d}^{-1}\right)$, and very heavy $\left(>50 \mathrm{~mm} \mathrm{~d}^{-1}\right)$ rain amounts for (a) all seasons and (b) summer only. Data are from the year 2015 and from the three countries considered in the study.

ases. The relationship between model performance and AOD is thus further investigated.

\subsubsection{Relationship between model performance and AOD}

In principle, the underestimation and overestimation at different rainfall levels (Figs. 3 and 4) may be linked to AOD conditions, as elaborated in the introduction of previous studies (cf. the review of Tao et al., 2012). The standard deviation of the forecast bias at each grid point in the three countries is calculated to further examine the links between the model bias and AOD. Aerosols tend to polarize precipitation by suppressing light rain and enhancing heavy rain and thus increase the standard deviation. The calculation of the standard deviation of the forecast difference is based on Eq. (7). Figure 5 shows the relationship between the standard deviation and AOD in the three countries. Each point represents a grid box. The standard deviation and AOD has a significant positive correlation in the three countries with correlation coefficients of $0.5602,0.6522$, and 0.5182 for Australia, the US, and China, respectively. This suggests that the degree of disparity of the forecast error is larger for grids with high aerosol loading. The slopes of the best-fit lines are 75.23 for relatively clean Australia (maximum AOD $<0.18$ ), 48.4 for the polluted US (maximum AOD $<0.20$ ), and 8.554 for heavily polluted China (maximum AOD $>0.60$ ).

The ETS and BIAS are used to examine the model performance under clean and polluted conditions for different AOD bins with fixed LWP (Fig. 6a and c) or RH (Fig. 6b and d) in the three countries. For a particular LWP or RH condition, the top and bottom one-third of AOD values are defined as polluted and clean subsets of data. In Fig. 6a and b, ETS increases as the LWP or RH increases. This is because largescale precipitation is diagnosed from cloud mixing ratios. The ETS are smaller for the polluted scenario than for the clean scenario, especially under high-LWP or high-RH con-
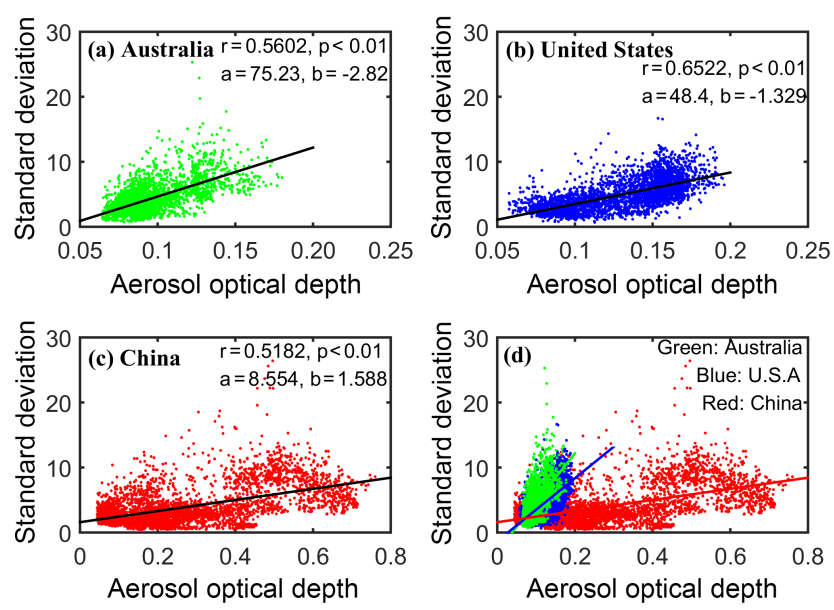

Figure 5. Standard deviations of the daily precipitation difference as a function of aerosol optical depth for (a) Australia (green points), (b) the United States (blue points), (c) China (red points), and (d) all three countries. Data are from the year 2015. The slopes (a) and $y$ intercepts (b) of the best-fit lines through the data in (a) to (c) are given, as well as the correlation coefficients $(r)$.

ditions. In Fig. $6 c$ and d, the BIAS decreases under polluted conditions compared with the BIAS under clean conditions. The decreases in ETS and BIAS under polluted conditions suggest that AOD influences the model rainfall forecast.

\subsection{Potential contribution of aerosols to the model bias}

\subsubsection{Long-term forecast bias and trends in observed precipitation in Fujian Province, China}

The model performance differs under different conditions, e.g., initial and dynamic settings, and weather regimes. A long-term statistical evaluation of rainfall forecasts for $\mathrm{Fu}-$ jian Province is made to mitigate these fluctuations in the model forecast accuracy. Model data from 1985 to 2010 are used to calculate the relative difference based on Eq. (8). Figure 7 shows the mean relative difference between forecast and observed precipitation for different rain rates from the 67 stations in Fujian Province for all seasons and for summer only. Figure 7a shows that there is $114.36 \%$ more precipitation forecast by the NCEP GEFS model than observed for the light rain cases. For moderate rain, heavy rain, and very heavy rain cases, $29.20,41.74$, and $59.30 \%$ less precipitation than observed, respectively, was forecast. The underestimation of moderate rain $(46.88 \%)$, heavy rain $(59.58 \%)$, and very heavy rain $(70.16 \%)$ is even larger in summer (Fig. $7 b$ ).

Seasonally averaged trends (percent change per decade) in daily rain amount and frequency over Fujian Province from 1980 to 2009 are calculated. Only the results for rain amount are shown in Fig. 8 because the frequency results bear a close resemblance. Cross-hatched bars represent data at a confidence level greater than $95 \%$. In spring, daily rain amounts decreased over time, ranging from -4.9 to $-15.3 \%$ 

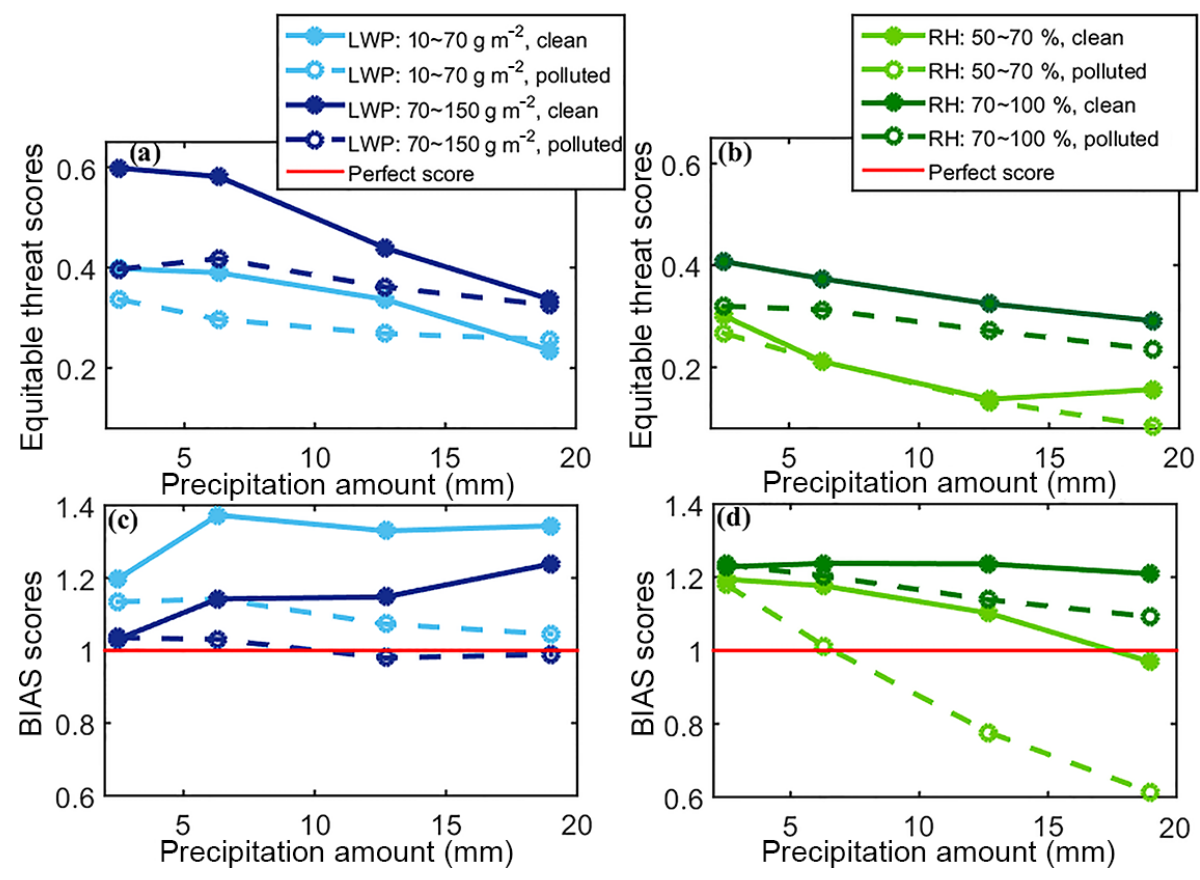

Figure 6. Equitable threat scores (a, b) and bias (BIAS) scores $(\mathbf{c}, \mathbf{d})$ as a function of precipitation amount for fixed ranges of liquid water path (LWP; a, c) and relative humidity $(\mathrm{RH} ; \mathbf{b}, \mathbf{d})$ under clean and polluted conditions. The LWP is divided into two categories: $10-70 \mathrm{~g} \mathrm{~m}^{-2}$ (light blue) and $70-150 \mathrm{~g} \mathrm{~m}^{-2}$ (dark blue). Data are from August 2015 in the US, China, and Australia. The RH is divided into two categories: $50-70 \%$ (light green) and 70-100\% (dark green). Data are from the year 2015. For a given LWP or RH condition, the top and bottom onethird of AOD values are defined as polluted and clean subsets of data, respectively. The solid lines represent the clean scenario, and the dotted lines represent the polluted scenario. The horizontal red lines in (c) and (d) represent perfect scores.
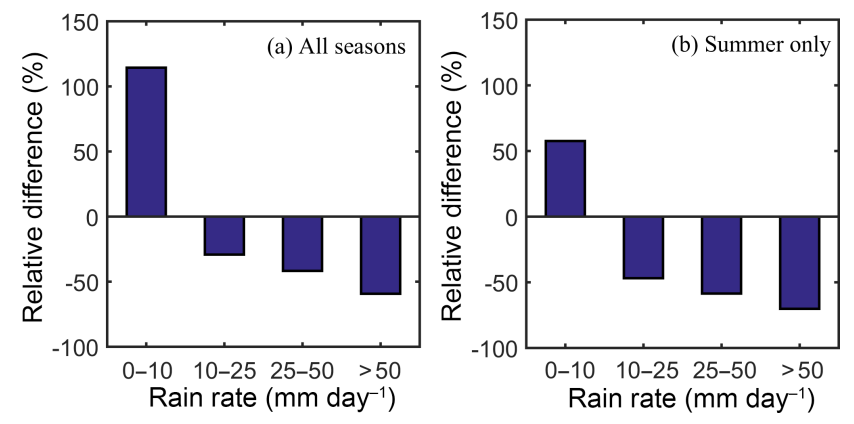

Figure 7. Mean relative precipitation differences between forecast and observed daily light $\left(<10 \mathrm{~mm} \mathrm{~d}^{-1}\right)$, moderate $\left(10-25 \mathrm{~mm} \mathrm{~d}^{-1}\right)$, heavy $\left(25-50 \mathrm{~mm} \mathrm{~d}^{-1}\right)$, and very heavy $\left(>50 \mathrm{~mm} \mathrm{~d}^{-1}\right)$ rain amounts for (a) all seasons and (b) summer only in Fujian Province, China. Data are from 1985 to 2010.

per decade for different rain rates. In summer, heavy and very heavy daily rain amounts increased significantly. For very heavy rain, the amount and frequencies increased at a rate of 21.8 and $24.5 \%$ (not shown), respectively. In autumn, light rain and moderate rain amounts decreased. In winter, the light rain amount decreased over time. Decreases in light rain amounts are $-8.4 \%$ per decade. Overall, the increasing trends in summertime for heavy and very heavy rain are most significant. The decreasing trends in light rain in other seasons are also significant.

\subsubsection{Examination of potential contributors}

Reasons for the difference between modeled and observed precipitation are examined in terms of aerosol effects, water vapor, and CAPE. Time series of visibility over the period of 1980-2009 are shown in Fig. 9. Visibility has declined steadily in all seasons but summer, during which there was a short-lived increasing trend from 1992 to 1997. The linear declining trends are statistically significant at the $95 \%$ confidence level. The greatest reduction is seen during the summer, especially after 1997. Tables 3 and 4 summarize the correlation between visibility and precipitation amount and frequency, respectively. A positive (negative) correlation between visibility and precipitation means a negative (positive) correlation between aerosol concentration and precipitation. Values with an asterisk represent data at a confidence level greater than $95 \%$. For light rain, the correlations between daily rain amount and visibility (Table 3 ) and between rain frequency and visibility (Table 4 ) are positive for all seasons. For heavy rain to very heavy rain, the correlations between visibility and daily rain amount (Table 3), as well as frequency (Table 4), are negative in summer. 

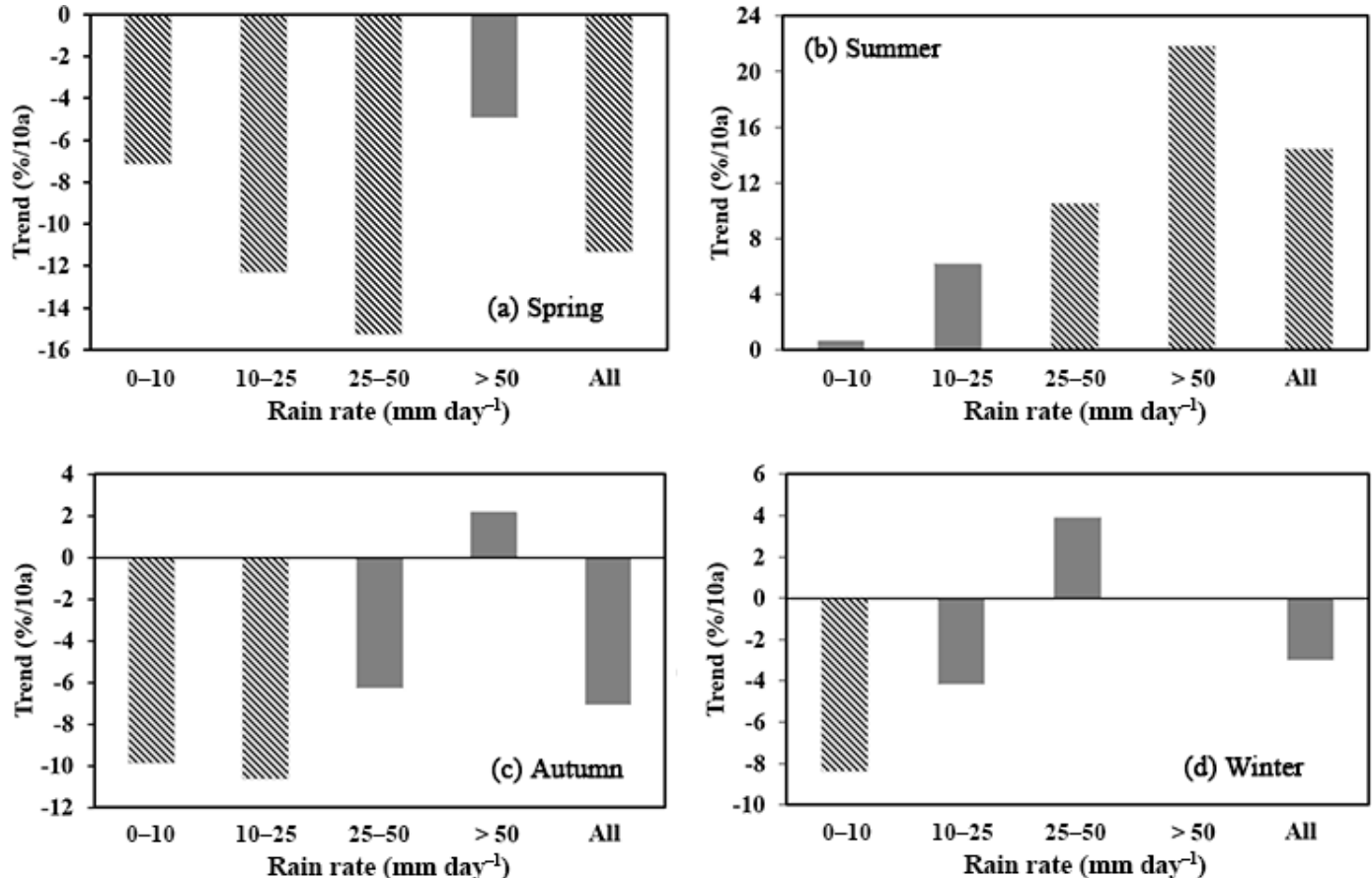

Figure 8. Trends (percent change per decade) in mean daily light rain $\left(<10 \mathrm{~mm} \mathrm{~d}^{-1}\right)$, moderate rain $\left(10-25 \mathrm{~mm} \mathrm{~d}^{-1}\right)$, heavy rain $(25-$ $\left.50 \mathrm{~mm} \mathrm{~d}^{-1}\right)$, very heavy rain $\left(>50 \mathrm{~mm} \mathrm{~d}^{-1}\right)$, and total rain amounts for (a) spring, (b) summer, (c) autumn, and (d) winter in Fujian Province, China. Data are from 1980 to 2009. Cross-hatched bars represent data at a confidence level greater than $95 \%$.
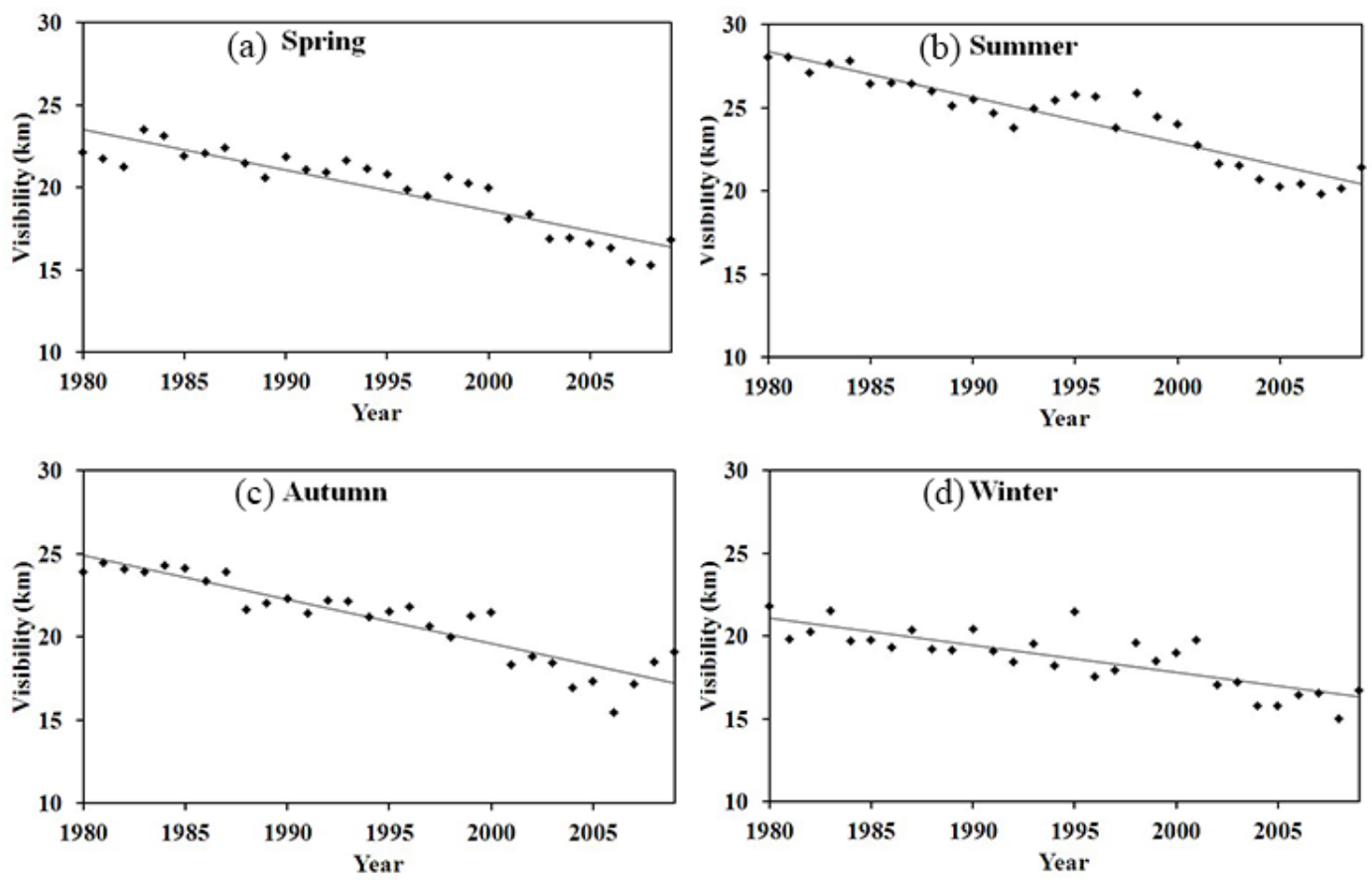

Figure 9. Annual mean visibilities in (a) spring, (b) summer, (c) autumn, and (d) winter in Fujian Province, China. Data are from 1980 to 2009. Least squares regression lines at the $95 \%$ confidence level are shown. 
Table 3. Correlation coefficients from linear regressions of visibility and different rain amount types for all seasons.

\begin{tabular}{|c|c|c|c|c|c|c|}
\hline & & \multicolumn{4}{|c|}{ Rain rate } & \multirow[b]{2}{*}{ Rain amount } \\
\hline & & Light rain & Moderate rain & Heavy rain & Very heavy rain & \\
\hline \multirow{4}{*}{ 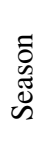 } & Spring & $0.48^{*}$ & $0.51^{*}$ & $0.48^{*}$ & 0.17 & $0.40^{*}$ \\
\hline & Summer & 0.08 & -0.16 & -0.28 & $-0.41^{*}$ & $-0.38^{*}$ \\
\hline & Autumn & 0.31 & 0.18 & 0.26 & -0.22 & 0.11 \\
\hline & Winter & $0.55^{*}$ & 0.26 & 0.26 & 0.27 & 0.29 \\
\hline
\end{tabular}

* Values with an asterisk represent data at a confidence level greater than $95 \%$.

Table 4. Correlation coefficients from linear regressions of visibility and different occurrence frequencies of rain amount type for all seasons.

\begin{tabular}{|c|c|c|c|c|c|c|}
\hline & & \multicolumn{4}{|c|}{ Rain rate } & \multirow[b]{2}{*}{ Rain amount } \\
\hline & & Light rain & Moderate rain & Heavy rain & Very heavy rain & \\
\hline \multirow{4}{*}{ 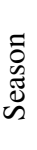 } & Spring & $0.61^{*}$ & $0.51^{*}$ & $0.38^{*}$ & 0.08 & $0.67^{*}$ \\
\hline & Summer & 0.23 & -0.13 & -0.26 & $-0.44^{*}$ & -0.04 \\
\hline & Autumn & $0.52^{*}$ & 0.18 & 0.25 & -0.10 & $0.45^{*}$ \\
\hline & Winter & $0.55^{*}$ & 0.22 & 0.20 & -0.05 & $0.49^{*}$ \\
\hline
\end{tabular}

* Values with an asterisk represent data at a confidence level greater than $95 \%$.

The water vapor amount and atmospheric stability are important factors related to precipitation. To analyze the potential contributions of these factors to the forecast bias, their effects on precipitation are examined. Data from three atmospheric sounding stations (Xiamen, $24.48^{\circ} \mathrm{N}, 118.08^{\circ} \mathrm{E}$; Shaowu, $27.33^{\circ} \mathrm{N}, 117.46^{\circ} \mathrm{E}$; Fuzhou, $26.08^{\circ} \mathrm{N}, 119.28^{\circ} \mathrm{E}$ ) collected from 1980 to 2009 are used to calculate trends in precipitable water vapor and CAPE. Figure 10 shows time series of annual mean water vapor amount for different seasons. A slight increasing trend is seen in winter, while no discernible trend is seen in other seasons. This suggests that the water vapor amount characterizing the study region cannot explain seasonal variations in precipitation. Time series of mean CAPE for the different seasons are shown in Fig. 11. There is an increasing trend in summertime CAPE during the period of 1980-2009, but the trends are not as strong in other seasons. The observed increase in rain amount in summer is in part likely due to an increase in convective precipitation events that arises from the increasing trend in CAPE.

\subsubsection{Impact of aerosols on clouds and precipitation}

Aerosols can influence precipitation through warm- and cold-rain processes (Tao et al., 2012). Cloud droplet size, LWP for clouds with CTT greater than $273 \mathrm{~K}$, and AOD at $550 \mathrm{~nm}$ retrieved from the Aqua MODIS platform over $\mathrm{Fu}-$ jian Province during the period of 2003-2012 are used to examine the impact of aerosols on cloud effective radius (CER). Figure 12 shows CER as a function of AOD for liquid clouds with different LWPs. When the AOD is small $(<0.2)$, the CER increases with increasing LWP. For LWP $>100 \mathrm{~g} \mathrm{~m}^{-2}$, the CER decreases with increasing AOD, which suggests that more aerosols decrease CERs. This result is in line with the two aerosol indirect effects (Twomey et al., 1984; Albrecht, 1989). A greater number of smaller droplets may reduce the precipitation efficiency and suppress or enhance precipitation, as reviewed by Tao et al. (2012).

Several observational and model studies suggest that smaller cloud particles are more likely to ascend to above the freezing level, releasing latent heat and invigorating deep convection (Rosenfeld et al., 2008; Li et al., 2011) while suppressing shallow convection. CTTs and CBTs, converted from CloudSat-CALIPSO measurements of cloud-top and base heights, in Fujian Province from 2006 to 2010 are used to study the impact of aerosols on the cloud development of different clouds. Figure 13 shows CTT as a function of AOD for liquid and warm- and cold-base mixed-phase clouds. Definitions of the different cloud types are summarized in Table 1, which is taken from Li et al. (2011). Left-hand ordinates are for liquid clouds, while right-hand ordinates are for warm-base and cold-base mixed-phase clouds. For all seasons (Fig. 13a), CTTs of warm-base mixed-phase clouds are lower than those of cold-base mixed-phase clouds. Warmbase mixed-phase CTTs decrease with increasing AOD, which indicates that cloud-top heights have increased. For cold-base mixed-phase clouds, variations in CTT with AOD are not obvious. For liquid clouds, CTTs increase slightly with AOD, which means that the development of liquid clouds is suppressed when AOD increases. The negative slope of the linear relationship between CTT and AOD for warm-base mixed-phase clouds and the positive slope of the linear relationship between CTT and AOD for liquid clouds are both stronger in summer (Fig. 13b). This suggests that 

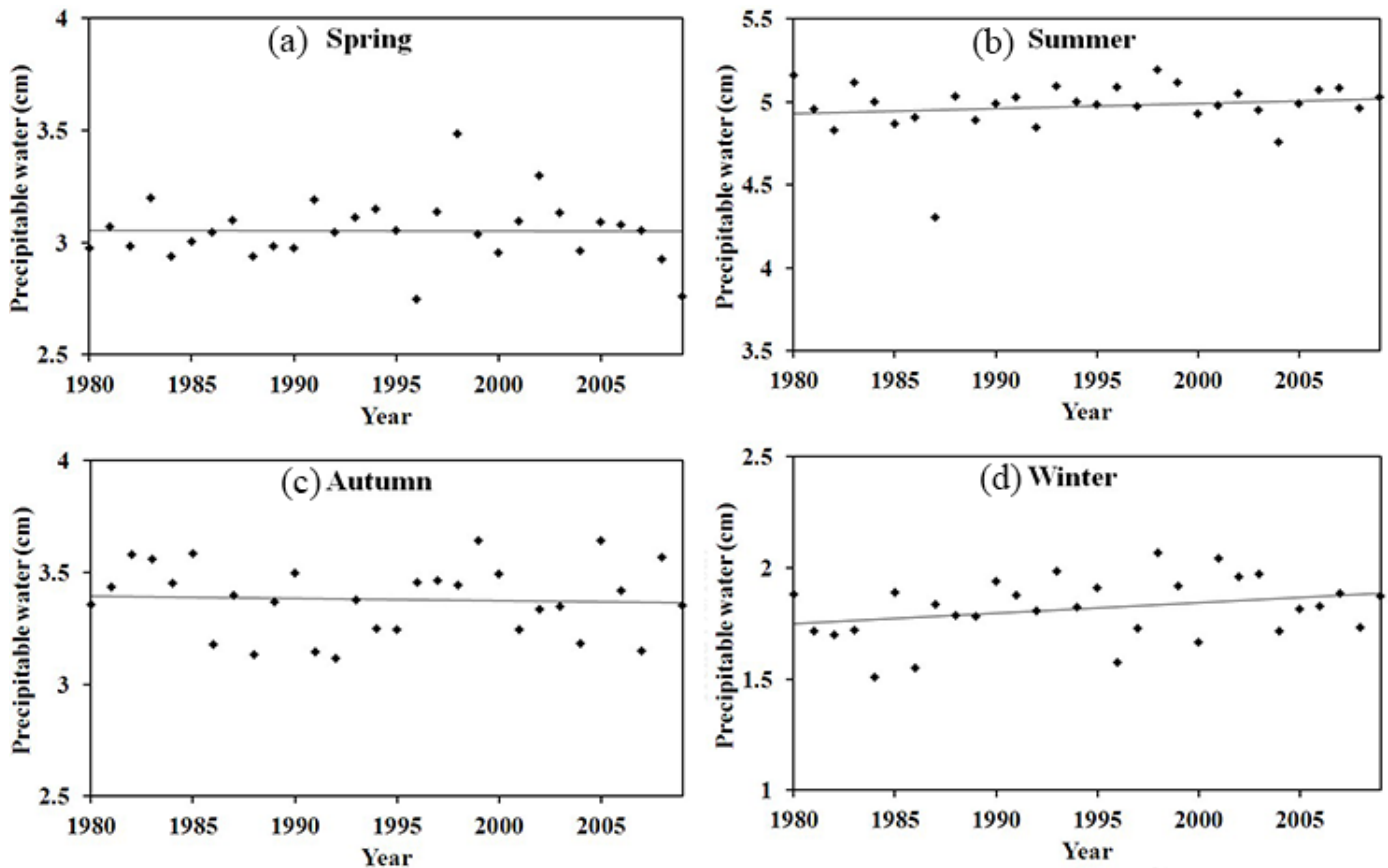

Figure 10. Same as Fig. 9, except for precipitable water vapor.
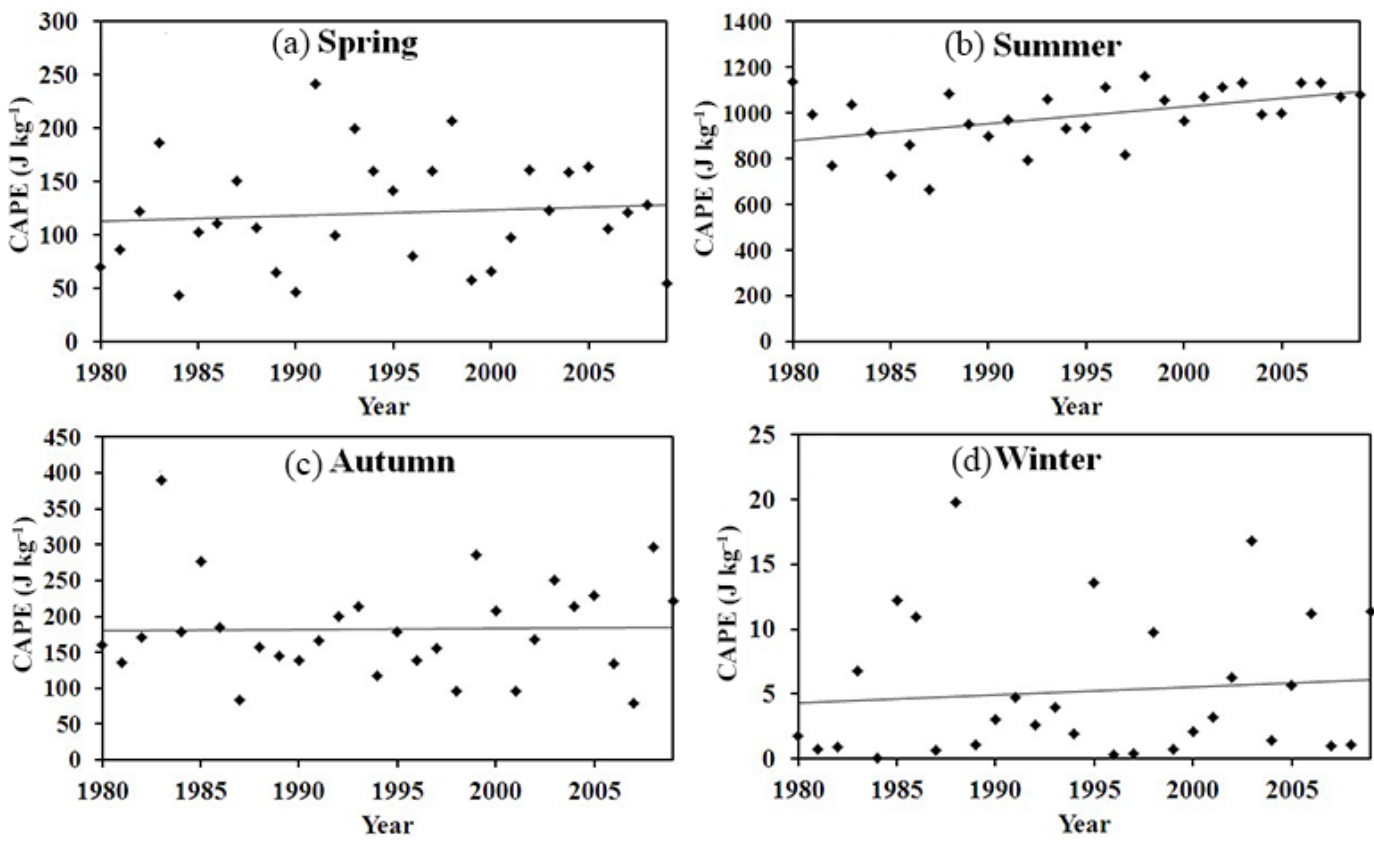

Figure 11. Same as Fig. 9, except for convective available potential energy (CAPE).

aerosols inhibit the development of shallow liquid clouds and invigorate warm-base mixed-phase clouds, with little influence on cold-base mixed-phase clouds. These effects of aerosols on summertime cloud development are more obvious, likely because convective clouds occur more frequently during the summertime in Fujian Province.
These results agree with those from a ground-based study using ARM Southern Great Plains data (Li et al., 2011) and from tropical region studies using CloudSat-Cloud-Aerosol Lidar and Infrared Pathfinder Satellite Observation data (Niu and $\mathrm{Li}, 2012$; Peng et al., 2016). The impact of aerosols on different types of clouds may lead to light-rain suppression and heavier-rain enhancement. If the GFS model ne- 


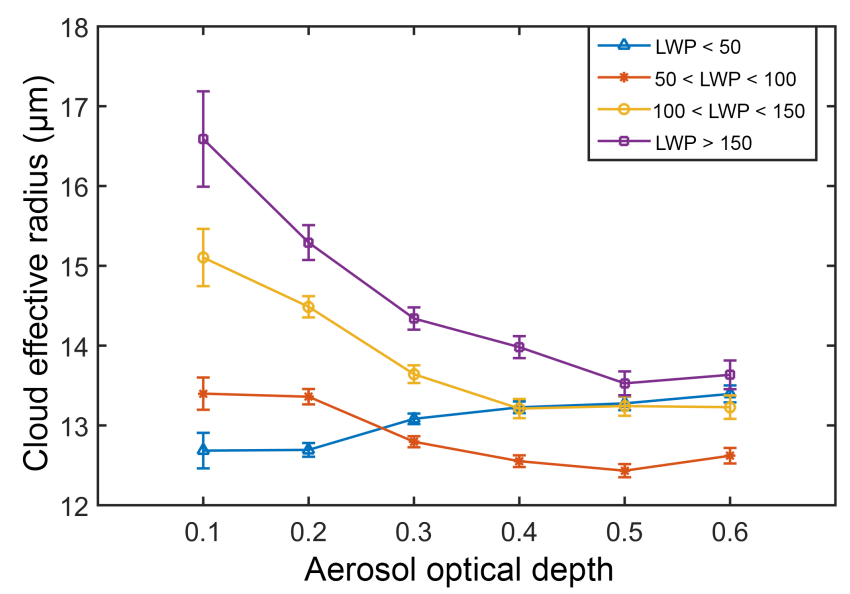

Figure 12. Cloud effective radius as a function of aerosol optical depth for liquid clouds (clouds with top temperatures greater than $273 \mathrm{~K}$ ) in Fujian Province, China. Blue triangles represent cases where the liquid water path (LWP) is less than $50 \mathrm{~g} \mathrm{~m}^{-2}$, orange stars represent LWPs between 50 and $100 \mathrm{~g} \mathrm{~m}^{-2}$, yellow circles represent LWPs between 100 and $150 \mathrm{~g} \mathrm{~m}^{-2}$, and purple squares represent LWPs greater than $150 \mathrm{~g} \mathrm{~m}^{-2}$. Error bars represent 1 standard error. Data are from 2003-2012.

glects aerosol effects, overestimations of light rain and underestimations of heavy to very heavy rain may be forecast, especially in summer. For example, Fig. 14 shows time series of regionally averaged daily modeled and observed precipitation in 2001. Modeled and observed precipitation amounts over the region agree well in spring and winter while modeled precipitation amounts are greater than observations for light rain in autumn. Note that modeled precipitation amounts are significantly less than observed precipitation amounts over the region in summer when deep convective clouds and heavy to very heavy rain tends to occur. Although there are many reasons for the difference between modeled and observed precipitation, these results suggest that to some extent, the neglect of aerosol effects may contribute to the model rainfall forecast bias.

\section{Summary and discussion}

ACIs have been recognized as playing a vital role in precipitation but have not been considered in the NCEP GFS model yet. For more efficient and accurate forecasts, new physical schemes are being incorporated into the NCEP's Next Generation Global Prediction System. As a benchmark evaluation of model results that exclude aerosol effects, the operational precipitation forecast (before any ACIs are included) is evaluated using multiple datasets with the goal of determining if there is any link between the model forecast bias and aerosol loading. Multiple datasets are used, including ground-based precipitation and visibility datasets, Aqua Moderate Resolution Imaging Spectroradiometer products,
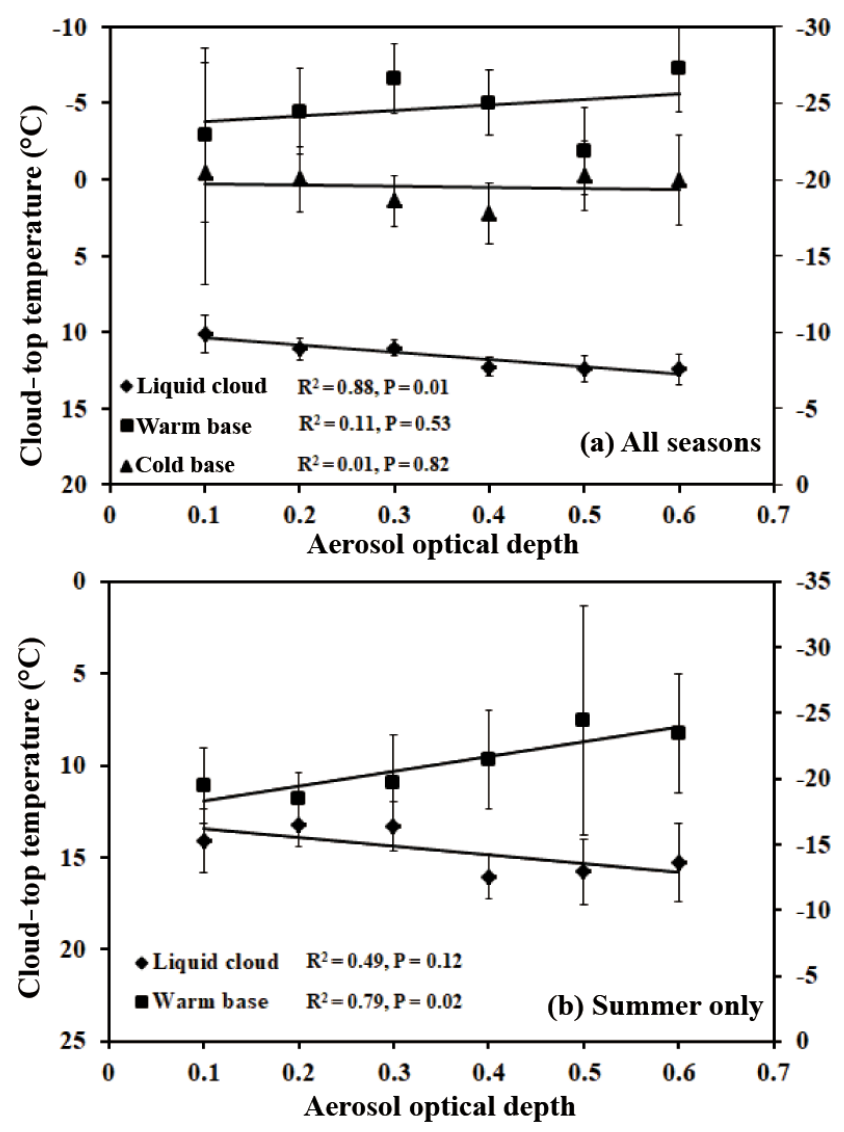

Figure 13. Cloud-top temperature as a function of aerosol optical depth for (a) liquid, warm-base mixed-phase, and cold-base mixed-phase clouds in all seasons and (b) liquid and warm-base mixed-phase clouds in summer in Fujian Province, China. Diamonds represent liquid clouds, squares represent warm-base mixedphase clouds, and triangles represent cold-base mixed-phase clouds. Right-hand ordinates are for warm-base and cold-base mixed-phase clouds. Data are from 2006 to 2010.

CloudSat-CALIPSO retrievals of cloud-base and cloud-top heights, Modern-Era Retrospective analysis for Research and Applications Version 2 model simulations of AOD, and GFS forecast datasets.

Operational daily precipitation forecasts for the year 2015 in three countries, i.e., Australia, the US, and China, were evaluated. The model overestimates light rain and underestimates moderate rain, heavy rain, and very heavy rain. The underestimation of precipitation in summer is even larger. This is consistent qualitatively with the expected results because the model does not account for aerosol effects on precipitation, i.e., the inhibition of light rain and the enhancement of heavy rain by aerosols. The standard deviations of forecast differences are generally positively correlated with increasing aerosol loadings in the three countries. Equitable threat scores and BIAS scores decrease for the polluted scenario. 

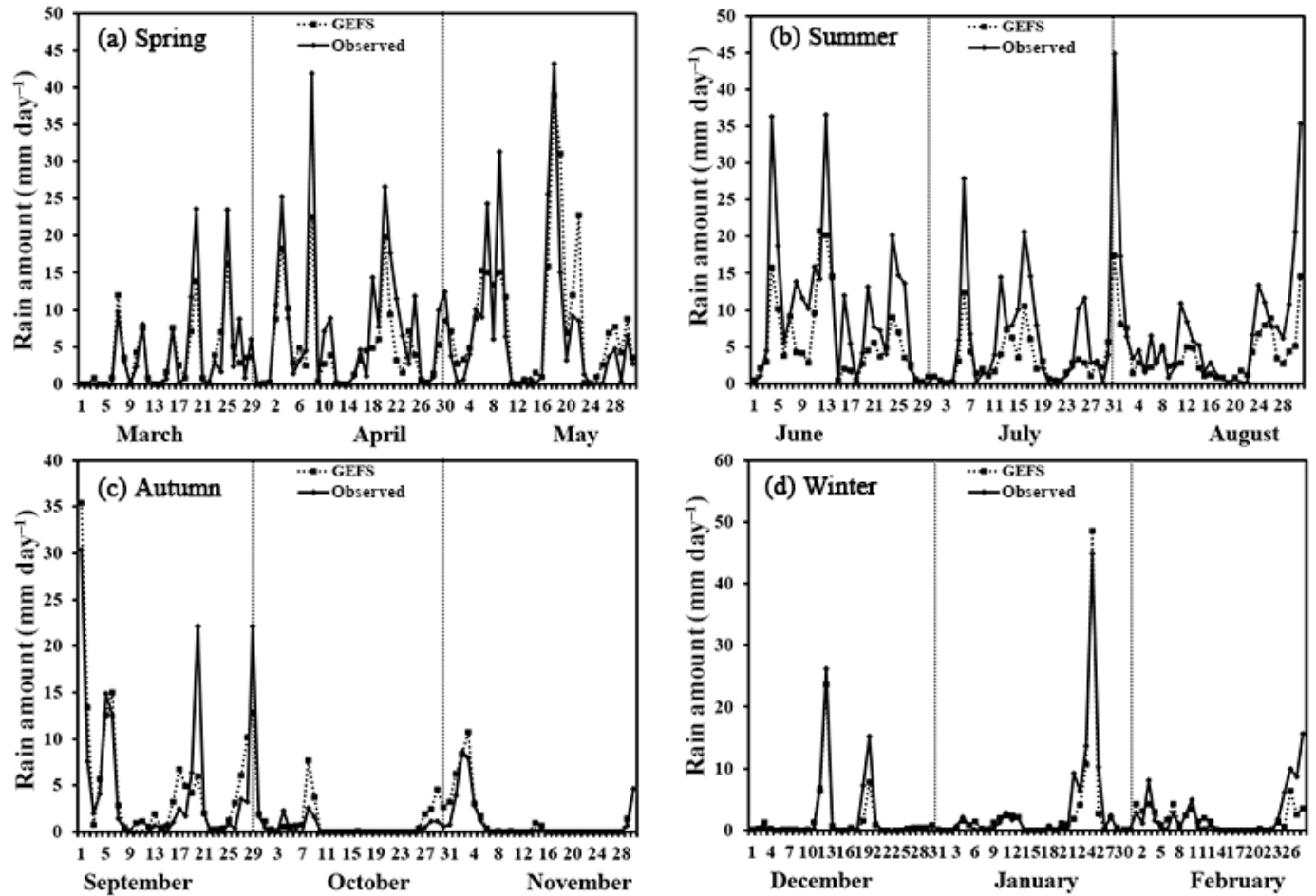

Figure 14. Time series of regionally averaged daily rainfall amount in Fujian Province, China, in (a) spring, (b) summer, (c) autumn, and (d) winter. Dotted lines represent rainfall forecasts from the Global Ensemble Forecast System, and solid lines represent rainfall measurements from gauge-based observations. Data are from 2001.

An analysis of long-term measurements from Fujian Province, China, was done. Light-rain overestimation and moderate-, heavy-, and very heavy-rain underestimations from the Global Ensemble Forecast System were also seen. The underestimation for stronger rainfall was larger in the summertime. Increasing trends for heavy and very heavy rain in summer and decreasing trends for light rainfall in other seasons were significant from 1980 to 2009. Long-term analyses show that neither water vapor nor convective available potential energy can explain these trends. Satellite datasets amassed in Fujian Province from 2006 to 2010 were used to shed more light on the impact of aerosols on cloud and precipitation. As implied by the Twomey effect, cloud effective radii decrease with increasing AOD, which likely suppresses light rain and enhances heavy rain. This may contribute to the model forecast bias to some extent. The underestimation of heavy rain in summer most likely occurs because deep convective clouds occur more frequently during the summertime in Fujian Province.

It remains an open question how neglecting ACI in the operational forecast model impacts model biases. This study is arguably the first attempt at evaluating numerical weather prediction forecast errors in terms of the potential effects of aerosols. A more rigorous and systematic evaluation to gain insights into the model is needed. Toward this goal, case- based investigations using rich instantaneous measurements are currently underway.

Data availability. Forecast data are from the NOAA NOMADS (https://nomads.ncdc.noaa.gov/) for GFS data (https://nomads.ncdc.noaa.gov/data/gfs4/) and the NOAA NCDC (https://www.ncdc.noaa.gov/data-access/model-data/ model-datasets/global-ensemble-forecast-system-gefs) for GEFS reforecast data. NASA MERRA-2 aerosol data are accessible from the NASA Global Modeling and Assimilation Office (https:// gmao.gsfc.nasa.gov/reanalysis/MERRA-2/data_access/). The CPC unified gauge-based analysis of global daily precipitation dataset is available at https://climatedataguide.ucar.edu/climate-data/ cpc-unified-gauge-based-analysis-global-daily-precipitation.

MODIS data and CloudSat-CALIPSO data are available at https://modis-atmosphere.gsfc.nasa.gov/MOD08_D3/index.html and http://www.cloudsat.cira.colostate.edu/, respectively. Groundbased observations of precipitation amount, visibility, precipitable water, and CAPE from Fujian Province can be requested from the Chinese Meteorological Administration's National Meteorological Information Center (http://data.cma.cn/). The retrieved data in the study are available upon request via email: jiangmj@mail.bnu.edu.cn (Mengjiao Jiang).

Competing interests. The authors declare that they have no conflict of interest. 
Special issue statement. This article is part of the special issue "Regional transport and transformation of air pollution in eastern China”. It is not associated with a conference.

Acknowledgements. This study was supported by the Ministry of Science and Technology of China (2013CB955804), the National Science Foundations of China (91544217) and of the US (AGS1534670), the Fundamental Research Funds for the Central Universities of China (312231103), the State Key Laboratory of Earth Surface Processes and Resource Ecology (2015-TDZD-090), and NOAA (NA15NWS4680011). We would like to thank the NASA Global Modeling and Assimilation Office (https://gmao.gsfc.nasa.gov/reanalysis/MERRA-2/data_access/) and the Goddard Space Flight Center Distributed Active Archive Center for their help in accessing MERRA-2 inst3_2d_gas_Nx: 2d, 3-Hourly, Instantaneous, Single-Level, Assimilation, Aerosol Optical Depth Analysis Version 5.12.4 data. We would like to thank the staff at the National Center for Atmospheric Research responsible for creating the "The Climate Data Guide: CPC Unified Gauge-Based Analysis of Global Daily Precipitation" (https://climatedataguide.ucar.edu/climate-data/ cpc-unified-gauge-based-analysis-global-daily-precipitation).

Thanks also go to the NOAA NOMADS (https: //nomads.ncdc.noaa.gov/) for GFS data (https://nomads. ncdc.noaa.gov/data/gfs4/), the NOAA NCDC (https: //www.ncdc.noaa.gov/data-access/model-data/model-datasets/ global-ensemble-forecast-system-gefs) for GEFS reforecast data, and the NWS CPC for data-downloading software (http://www.cpc.ncep.noaa.gov/products/wesley/get_gfs.html).

We acknowledge the Chinese Meteorological Administration's National Meteorological Information Center (http://data.cma.cn/), the NASA Goddard Space Flight Center (https://modis-atmosphere.gsfc.nasa.gov/), and the CloudSat Data Processing Center (http://www.cloudsat.cira.colostate.edu/) for providing the various datasets used in the study.

We would also like to thank Shrinivas Moorthi and Jun Wang from NOAA, Sarah Lu from State University of New York, Albany, Seoung-Soo Lee from the University of Maryland, and Duoying Ji and Lanning Wang from Beijing Normal University for their discussions regarding this study. We especially appreciate the help given by Jongil Han in understanding the GFS/GEFS models and data products and the guidance provided by Hye-Lim Yoo. We also greatly appreciate the valuable comments from the anonymous reviewers.

Edited by: Jianping Huang

Reviewed by: two anonymous referees

\section{References}

Ackerman, A. S., Toon, O. B. , Stevens, D. E., Heymsfield, A. J., Ramanathan, V., and Welton, E. J.: Reduction of tropical cloudiness by soot, Science, 288, 1042-1047, https://doi.org/10.1126/science.288.5468.1042, 2000.

Albrecht, B. A.: Aerosols, cloud microphysics, and fractional cloudiness, Science, 245, 1227-1230, https://doi.org/10.1126/science.245.4923.1227, 1989.
Andreae, M. O., Rosenfeld, D., Artaxo, P., Costa, A. A., Frank, G. P., Longo, K. M., and Silva-Dias, M. A. F.: Smoking rain clouds over the Amazon, Science, 303, 1337-1342, https://doi.org/10.1126/science.1092779, 2004.

Appel, B. R., Tokiwa, Y., Hsu, J., Kothny, E. L., and Hahn, E.: Visibility as related to atmospheric aerosol constituents, Atmos. Environ., 19, 1525-1534, https://doi.org/10.1016/j.bbr.2011.03.031, 1985.

Arakawa, A. and Schubert, W. H.: Interaction of a cumulus cloud ensemble with the large-scale environment - Part I, J. Atmos. Sci., 31, 674-701, https://doi.org/10.1175/15200469(1974)031<0674:IOACCE>2.0.CO;2, 1974.

Bell, T., Rosenfeld, D., Kim, K., Yoo, J., Lee, M., and Hahnenberger, M.: Midweek increase in U.S. summer rain and storm heights suggests air pollution invigorates rainstorms, J. Geophys. Res. Atmos., 113, D02209, https://doi.org/10.1029/2007JD008623, 2008.

Carrió, G. G., Cotton, W. R., and Cheng, W. Y. Y.: Urban growth and aerosol effects on convection over Houston Part I: The August 2000 case, Atmos. Res., 96, 560-574, https://doi.org/10.1016/j.atmosres.2010.01.005, 2010.

Charlson, R. J.: Atmospheric visibility related to aerosol mass concentration: Review, Environ. Sci. Technol., 3, 913-918, https://doi.org/10.1021/es60033a002, 1969.

Chin, M., Ginoux, P., Kinne, S., Torres, O., Holben, B., Duncan, B. N., Martin, R. V., Logan, J., Higurashi, A., and Nakajima, T.: Tropospheric aerosol optical thickness from the GOCART model and comparisons with satellite and Sun photometer measurements, J. Atmos. Phys., 59, 461-483, https://doi.org/10.1175/15200469(2002)059<0461:TAOTFT>2.0.CO;2, 2002.

China Meteorological Administration (CMA): Ground meteorological data acquired in Fujian province, http://data.cma.cn/, 19802009.

CloudSat Data Processing Center: 2B-GEOPROF-LIDAR P2_R04, available at: http://www.cloudsat.cira.colostate.edu/ data-products/level-2b/2b-geoprof-lidar?term=48, 2016-2010a.

CloudSat Data Processing Center: ECMWF-AUX P_R04, available at: http://www.cloudsat.cira.colostate.edu/data-products/ level-aux/ecmwf-aux?term=64, 2006-2010b.

da Silva, A., Colarco, P. R., Darmenoy, A. S., Buchard-Marchant, V., Randles, C. A., and Gupta, P.: An overview of the GEOS-5 Aerosol Reanalysis, American Geophysical Union, Fall Meeting 2011, San Francisco, CA, USA, A52D-09, 2011.

Fan, J. W., Rosenfeld, D., Yang, Y., Zhao, C., Leung, L. R., and Li, Z.: Substantial contribution of anthropogenic air pollution to catastrophic floods in Southwest China, Geophys. Res. Lett., 42, 6066-6075, https://doi.org/10.1002/2015GL064479, 2015.

Fan, J. W., Wang, Y., Rosenfeld, D., and Liu, X.: Review of aerosolcloud interactions: mechanisms, significance, and challenges, J. Atmos. Sci., 73, 4221-4252, https://doi.org/10.1175/JAS-D-160037.1, 2016.

GCWM Branch, EMC: The GFS atmospheric model, NCEP Office Note 442, 14 pp., available at: http://wwwt.emc.ncep.noaa.gov/ officenotes, 2003.

Grell, G. A.: Prognostic evaluation of assumptions used by cumulus parameterizations, Mon. Weather Rev., 121, 764-787, https://doi.org/10.1175/15200493(1993)121<0764:PEOAUB>2.0.CO;2, 1993. 
Gryspeerdt, E., Stier, P., and Partridge, D. G.: Satellite observations of cloud regime development: the role of aerosol processes, Atmos. Chem. Phys., 14, 1141-1158, https://doi.org/10.5194/acp14-1141-2014, 2014a.

Gryspeerdt, E., Stier, P., and Partridge, D. G.: Links between satellite-retrieved aerosol and precipitation, Atmos. Chem. Phys., 14, 9677-9694, https://doi.org/10.5194/acp-149677-2014, 2014b.

Han, J. and Pan, H. L.: Revision of convection and vertical diffusion schemes in the NCEP Global Forecast System, Weather Forecast., 26, 520-533, https://doi.org/10.1175/WAF-D-10-05038.1, 2011.

Han, J., Witek, M. L., Teixeira, J., Sun, R., Pan, H. L., Fletcher, J. K., and Bretherton, C. S.: Implementation in the NCEP GFS of a Hybrid Eddy-Diffusivity Mass-Flux (EDMF) boundary layer parameterization with dissipative heating and modified stable boundary layer mixing, Weather Forecast., 31, 341-352, https://doi.org/10.1175/WAF-D-15-0053.1, 2016.

Hong, S. Y. and Pan, H. L.: Nonlocal boundary layer vertical diffusion in a medium-range forecast model, Mon. Weather Rev., 124, 2322-2339, https://doi.org/10.1175/15200493(1996)124<2322:NBLVDI>2.0.CO;2, 1996.

Intergovernmental Panel on Climate Change: Climate Change 2013: The Physical Science Basis, in Contribution of Working Group I to the Fifth Assessment Report of the Intergovernmental Panel on Climate Change, Cambridge Univ. Press, Cambridge, UK, 2013.

Jiang, H., Xue, H., Teller, A., Feingold, G., and Levin, Z.: Aerosol effects on the lifetime of shallow cumulus, Geophys. Res. Lett., 33, L14806, https://doi.org/10.1029/2006g1026024, 2006.

Jiang, M., Li, Z., Wan, B., and Cribb, M.: Impact of aerosols on precipitation from deep convective clouds in eastern China, J. Geophys. Res. Atmos., 121, 9607-9620, https://doi.org/10.1002/2015JD024246, 2016.

Kanamitsu, M.: Description of the NMC Global Data Assimilation and Forecast System, Weather Forecast., $\quad 4, \quad 335-342, \quad$ https://doi.org/10.1175/15200434(1989)004<0335:DOTNGD>2.0.CO;2, 1989.

Kaufman, Y., Koren, I., Remer, L., Rosenfeld, D., and Rudich, Y.: The effect of smoke, dust, and pollution aerosol on shallow cloud development over the Atlantic Ocean, P. Natl. Acad. Sci. USA, 102, 11207-11212, https://doi.org/10.1073/pnas.0505191102, 2005.

Khain, A., Benmoshe, N., and Pokrovsky, A.: Factors determining the impact of aerosols on surface precipitation from clouds: An attempt at classification, J. Atmos. Sci., 65, 1721-1748, https://doi.org/10.1175/2007JAS2515.1, 2008.

Koren, I., Kaufman, Y. J., Rosenfeld, D., Remer, L. A., and Rudich, Y.: Aerosol invigoration and restructuring of Atlantic convective clouds, Geophys. Res. Lett., 32, L14828, https://doi.org/10.1029/2005g1023187, 2005.

Koren, I., Martins, J. V., Remer, L. A., and Afargan, H.: Smoke invigoration versus inhibition of clouds over the Amazon, Science, 321, 946-949, https://doi.org/10.1126/science.1159185, 2008.

Li, Z., Niu, F., Fan, J., Liu, Y., Rosenfeld, D., and Ding, Y.: Long-term impacts of aerosols on the vertical development of clouds and precipitation, Nat. Geosci., 4, 888-894, https://doi.org/10.1038/ngeo1313, 2011.
Li, Z., Lau, W. K.-M., Ramanathan, V., Wu, G., Ding, Y., Manoj, M. G., Liu, J., Qian, Y., Li, J., Zhou, T., Fan, J., Rosenfeld, D., Ming, Y., Wang, Y., Huang, J., Wang, B., Xu, X., Lee, S.-S., Cribb, M., Zhang, F., Yang, X., Zhao, C., Takemura, T., Wang, K., Xia, X., Yin, Y., Zhang, H., Guo, J., Zhai, P. M., Sugimoto, N., Babu, S. S., and Brasseur, G. P.: Aerosol and monsoon climate interactions over Asia, Rev. Geophys., 54, 866-929, https://doi.org/10.1002/2015RG000500, 2016.

Lin, Y. and Zhao, C.: Trends of precipitation of different intensity in China, Acta Scientiarum Naturalium Universitatis Pekinensis, 45, 995-1002, 2009.

Lin, J. C., Matsui, T., Pielke, R. A., and Kummerow, C.: Effects of biomass-burning-derived aerosols on precipitation and clouds in the Amazon Basin: a satellite-based empirical study, J. Geophys. Res.-Atmos., 111, D19204, https://doi.org/10.1029/2005jd006884, 2006.

Moorthi, S., Pan, H. L., and Caplan, P.: Changes to the 2001 NCEP operational MRF/AVN global analysis/forecast system, NWS Technical Procedures Bulletin, 484, available at: www.nws.noaa. gov/om/tpb/484.htm, 2001.

NASA/GSFC/GMAO: MERRA-2 inst3_2d_gas_Nx: 2d, 3-Hourly, Instantaneous, Single-Level, Assimilation, Aerosol Optical Depth Analysis Version 5.12.4 data, available at: https://disc.sci. gsfc.nasa.gov/datasets?page=1\&keywords=MERRA-2, 2015.

NASA MODIS Atmosphere Science Team: Atmosphere Level-3 (Collection 5.1) Product Group/MODIS Adaptive Processing System (MODAPS), MYD08_D3, available at: https: //modis-atmosphere.gsfc.nasa.gov/MOD08_D3/index.html, 2003-2012.

Niu, F. and Li, Z.: Systematic variations of cloud top temperature and precipitation rate with aerosols over the global tropics, Atmos. Chem. Phys., 12, 8491-8498, https://doi.org/10.5194/acp12-8491-2012, 2012.

NOAA/CPC: CPC unified gauge-based precipitation data, available at: http://ftp.cpc.ncep.noaa.gov/precip/CPC_UNI_PRCP/ GAUGE_GLB/RT/, 2015.

NOAA/NCEP: GEFS data, available at: https://www. ncdc.noaa.gov/data-access/model-data/model-datasets/ global-ensemble-forecast-system-gefs, 1985-2010.

NOAA/NCEP: GFS data, available at: https://nomads.ncdc.noaa. gov/data/gfs4/, 2015.

Pan, H. L. and Wu, W. S.: Implementing a mass flux convective parameterization package for the NMC Medium-Range Forecast model, NMC Office Note 409, 40 pp., 1995.

Peng, J., Li, Z., Zhang, H., Liu, J., and Cribb, M. C.: Systematic changes in cloud radiative forcing with aerosol loading for deep clouds in the tropics, J. Atmos. Sci., 73, 231-249, https://doi.org/10.1175/JAS-D-15-0080.1, 2016.

Randles, C. A., da Silva, A. M., Buchard, V., Darmenoy, A., Colarco, P. R., Aquila, V., Bian, H., Nowottnick, E. P., Pan, X., Smirnov, A., Yu, H., and Govindaraju, R.: The MERRA2 Aerosol Assimilation, NASA Tech. Rep. Series on Global Modeling and Data Assimilation, NASA TM-2016-104606, 45, 156 pp., 2016.

Rienecker, M. M., Suarez, M. J., Gelaro, R., Todling, R., Bacmeister, J., Liu, E., Bosilovich, M. G., Schubert, S. D., Takacs, L., Kim, G. K., Bloom, S., Chen, J., Collins, D., Conaty, A., da Silva, A., Gu, W., Joiner, J., Koster, R. D., Lucchesi, R., Molod, A., Owens, T., Pawson, S., Pegion, P., Redder, C. R., Reichle, 
R., Robertson, F. R., Ruddick, A. G., Sienkiewicz, M., and Woollen, J.: MERRA: NASA's Modern-Era Retrospective Analysis for Research and Applications, J. Climate, 24, 3624-3648, https://doi.org/10.1175/JCLI-D-11-00015.1, 2011.

Rosenfeld, D.: Suppression of rain and snow by urban and industrial air pollution, Science, 287, 1793-1796, https://doi.org/10.1126/science.287.5459.1793, 2000.

Rosenfeld, D., Dai, J., Yu, X., Yao, Z., Xu, X., Yang, X., and $\mathrm{Du}, \mathrm{C} .:$ Inverse relations between amounts of air pollution and orographic precipitation, Science, 315, 1396-1398, https://doi.org/10.1126/science.1137949, 2007.

Rosenfeld, D., Lohmann, U., Raga, G. B., Dowd, C. D. O., Kulmala, M., Fuzzi, S., Reissell, A., and Andreae, M. O.: Flood or drought: How do aerosols affect precipitation?, Science, 321, 1309-1313, https://doi.org/10.1126/science.1160606, 2008.

Sela, J.: Implementation of the sigma pressure hybrid coordinate into GFS; NCEP Office, Note no. 461, available at http://www. emc.ncep.noaa.gov/officenotes/FullTOC.html\#2000, 2009.

Sundqvist, H., Berge, E., and Kristjansson, J. E.: Condensation and cloud parameterization studies with a mesoscale numerical weather prediction model, Mon. Weather Rev., 117, 1641-1657, https://doi.org/10.1175/15200493(1989)117<1641:CACPSW>2.0.CO;2, 1989.

Tao, W. K., Chen, J. P., Li, Z., Wang, C., and Zhang, C.: Impact of aerosols on convective clouds and precipitation, Rev. Geophys., 50, RG2001, https://doi.org/10.1029/2011rg000369, 2012.

Tapiador, F. J., Turk, F. J., Petersen, W., Hou, A. Y., García-Ortega, E., Machado, L. A., Angelis, C. F., Salio, P., Kidd, C., Huffman, G. J., and De Castro, M.: Global precipitation measurement: Methods, datasets and applications, Atmos. Res., 104, 7097, https://doi.org/10.1016/j.atmosres.2011.10.021, 2012.

Troen, I. and Mahrt, L.: A simple model of the atmospheric boundary layer: Sensitivity to surface evaporation, Bound.-Lay. Meteorol., 37, 129-148, https://doi.org/10.1007/BF00122760, 1986.

Twomey, S. A., Piepgrass, M., and Wolfe, T. L.: An assessment of the impact of pollution on global cloud albedo, Tellus B, 36, 356366, https://doi.org/10.1111/j.1600-0889.1984.tb00254.x, 1984.

van den Heever, S. C., Stephens, G. L., and Wood, N. B.: Aerosol indirect effects on tropical convection characteristics under conditions of radiative-convective equilibrium, J. Atmos. Sci., 68, 699-718, https://doi.org/10.1175/2010JAS3603.1, 2011.
Xie, P. P., Yatagai, A., Chen, M. Y., Hayasaka, T., Fukushima, Y., Liu, C. M., and Yang, S.: A gauge-based analysis of daily precipitation over East Asia, J. Hydrometeorol., 8, 607-626, https://doi.org/10.1175/Jhm583.1, 2007.

Xue, H. and Feingold, G.: Large-eddy simulations of trade wind cumuli: investigation of aerosol indirect effects, J. Atmos. Sci., 63, 1605-1622, https://doi.org/10.1175/JAS3706.1, 2006.

Yang, F. L., Pan., H. L., Krueger, S. K., Moorthi, S., and Lord, S. J.: Evaluation of the NCEP Global Forecast System at the ARM SGP site, Mon. Weather Rev., 134, 3668-3690, https://doi.org/10.1175/MWR3264.1, 2006.

Yang, $\mathrm{X}$. and Li, Z.: Increases in thunderstorm activity and relationships with air pollution in southeast China, J. Geophys. Res.-Atmos., 119, 1835-1844, https://doi.org/10.1002/2013JD021224, 2014.

Yang, X., Ferrat, M., and Li, Z.: New evidence of orographic precipitation suppression by aerosols in central China, Meteor. Atmos. Phys., 119, 17-29, https://doi.org/10.1007/s00703-012-0221-9, 2013.

Yoo, H. and Li, Z.: Evaluation of cloud properties in the NOAA/NCEP global forecast system using multiple satellite products, Clim. Dynam., 39, 2769-2787, https://doi.org/10.1007/s00382-012-1430-0, 2012.

Yoo, H., Li, Z., Hou, Y.-T, Lord, S., Weng, F., and Barker, H. W.: Diagnosis and testing of low-level cloud parameterizations for the NCEP/GFS model satellite and ground-based measurements, Clim. Dynam., 41, 1595-1613, https://doi.org/10.1007/s00382013-1884-8, 2013.

Zhang, J., Reid., J., and Holben, B.: An analysis of potential cloud artifacts in MODIS over ocean aerosol optical thickness products, Geophys. Res. Lett., 32, L15803, https://doi.org/10.1029/2005GL023254, 2005.

Zhao, Q. Y. and Carr, F. H.: A prognostic cloud scheme for operational NWP models, Mon. Weather Rev., 125, 1931-1953, https://doi.org/10.1175/15200493(1997)125<1931:APCSFO>2.0.CO;2, 1997. 